تاريخ الإرسال (01-09-2020)، تاريخ قبول النشر (2020-11)

د. أمامة محمد الشنقيطي

كلية التربية -جامعة الأميرة نورة بنت عبد الرحمن - الرمبة

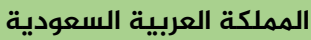

* البريد الالكتروني للباحث المرسل:

E-mail address:

omfal@pnu.edu.sa
اسم الباحث:

و اقع الممارسات التلدريسية لهملمات اللفة العربية في المملكة العربية السعودية لتنمية

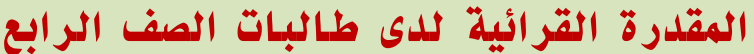
الابتدائي ووفت مؤشرات اختبار بير لز (Pirls)

https://doi.org/10.33976/IUGJEPS.29.4/2021/17

هدفت الدراسة إلى، الكشف عن واقع الممارسات التدريسية لمعلمات اللغة العربية في المملكة العربية السعودية لتنمية المقدرة القرائية لدى طالبات الصف الرابع الابتدائي وفق مؤشرات اختبار بيرلز، وتم توظيف المنهج الوصفي، ولتحقيق أهداف الدراسة. صممت الاستبانة، وبعد التأكد من صدقها وثباتها تم تطبيقها على عينة بلغ قوامها (400) معلمة من مدينة الرياض وجدة وعرعر. وكشفت نتائج الدراسة عن درجات عالية في الممارسات التدريسية الهادفة إلى تنمية المقدرة القرائية حسب إجابات العينة، وهذه النتيجة التي تعارض ما أسفرت عنه التقارير الرسمية عن نتائج مشاركة المملكة العربية السعودية في اختبار (بيرلز)، وتحتاج إلى تفسيرها، كما كشفت النتائج من أن هناك فرقاً دالا إحصائياً في الممارسات التدريسية في المستوى الرابع بين معلمات اللغة العربية في مدينة الرياض وجدة وعرعر، لصالح مدينة الرياض. وقد تدفع هذه النتيجة إلى المزيد من التقصي حول أسبابها. وقد أوصت الدراسة بعقد دورات لتدريب المعلمين والمعلمات في أثناء الخدمة بهدف تنمية مهارات المعلمين في الارتقاء بالمقدرة القرائية لدى طلابهم، مع قياس أثر التدريب. واقترحت إجراء دراسات تربط نتائج الاختبار الدولي في المقدرة القرائية بعدة عوامل منها ما يتعلق بالطالب أو المعلم أو المنهج أو الأسرة والمجتمع.

كلمات مفتامية: الممارسات التدريسية -معلمات اللفة العربية - المقدرة القرائية - اختبار بيرلز (Pirls) .

The reality of teaching practice for Arabic language teachers in the Kingdom of Saudi Arabia to develop the literacy ability of fourth-grade students according to the Pirls test indicators

\title{
Abstract:
}

The study aimed to uncover the reality of the practices of teaching Arabic language teachers in the Kingdom of Saudi Arabia to develop the reading ability of students according to the Perles test indicators. The descriptive approach was employed, and to achieve the objectives of the study. The questionnaire was designed, and after making sure of its validity and reliability, it was applied to a sample of (400) teachers from Riyadh, Jeddah and Arar. The results of the study revealed high scores in teaching practices aimed at developing the literacy ability according to the sample answers, and this result contradicts what was revealed by the official reports on the results of the participation of the Kingdom of Saudi Arabia in the (Pirls) test, and needs to be interpreted, as the results revealed that there is a difference. Statistically significant in teaching practices at the fourth level among Arabic language teachers in Riyadh, Jeddah and Arar, for the city of Riyadh. This finding may prompt further investigation of its causes. The study recommended holding in-service training courses for teachers with the aim of developing teachers' skills in improving the reading ability of their students, while measuring the impact of training. It suggested conducting studies that link the results of the international test on literacy ability with several factors, including those related to the student, teacher, curriculum, family and society.

|Keywords: Teaching Practices - Arabic Language Teacher - Reading ability- Pirls 
نالت القراءة مكانة بارزة في الاتصال؛ نتيجة لوجود علاقة طردية بين أهمية تعلم القراءة ما يسود العالم من ثورة معرفية هائلة في شتى المجالات. وأصبح لتعلمها وتعليمها الصدارة بين فروع اللغة العربية؛ نظرا لإسهاماتها في تربية الجيل تربية متكاملة. (يونس،

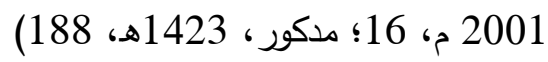

وتعد القراءة عملية ذهنية معقدة تتطلب استتفار القدرات الوجدانية والعقلية في إجراءات منهجية تتدرج بدءا بالملاحظة والفهم وانتقالا إلى التحليل والتركيب وانتهاء بنقد المقروء والتفاعل معه؛ ومن هنا برزت الحاجة إلى ضرورة تدريب المتعلمين على تعبئة مكتسباتهم الوجدانية والمعرفية والمهارية على الارتقاء من فك رموز المقروء إلى بناء المعنى واستكثاف عوالم النص. (أتزكي

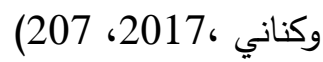
ولأن الفهم القرائي هو أساس تعلم المقروء، والاستفادة منه، فقد أصبح محط اهتمام عدد من المؤلفين والباحثين: ففصلوا في تفسيره، وتحديد مستوياته، ومهاراته، وأصبح من أهم أهداف التعليم في المرحلة الابتدائية؛ بصفتها مرحلة تكوين المهارات وبناء

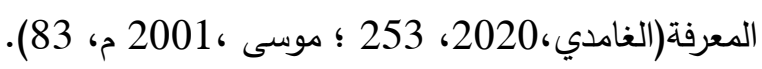

واتقق التربويون على أن الفهم القرائي عملية عقلية معقدة غير قابلة للملاحظة المباشرة؛ حيث إن القارئ يفهم النص من خلال

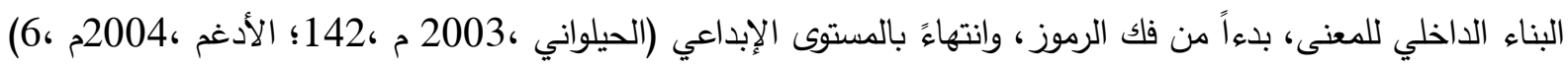
كما يوصف بأنه استراتيجية تتسم بالبنائية، لأنها تتطلب استحضار القارئ لخبراته السابقة وربطها بالمقروه، مستخدما

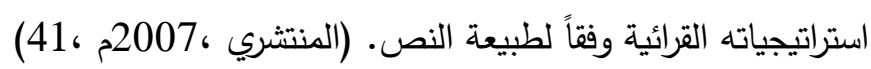

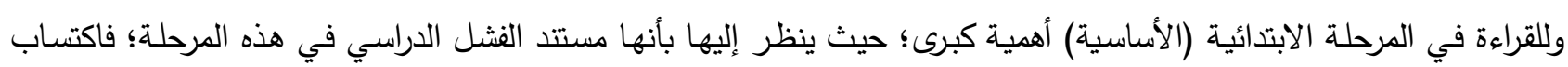

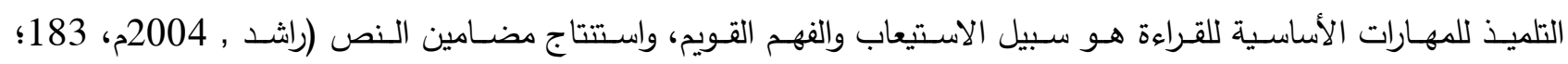

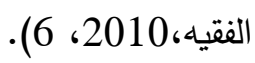
ومن المؤكد أن الفهم القرائي عملية تثمل الربط بين رموز الكلمات ومعانيها، وتقويم المعاني، وتتظيم الأفكار في أثناء القراءة،

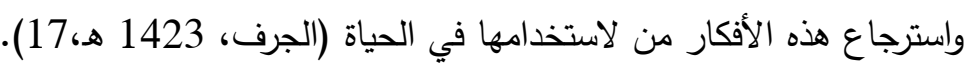

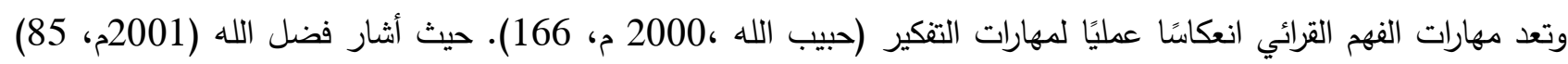
إلى أن مستويات الفهم القرائي هي: المستوى الحرفي، والمستوى التفسيري، والمستوى التطبيقي. في حين صنف الناقة وحافظ (2002م ،215 -218) مستويات الفهم القرائي إلى: مستوى الفهم المباشر ومستوى الفهم الاستتاجي، ومستوى الفهم النقدي، ثم مستوى الفهم التذوقي، وأخيرا مستوى الفهم الإبداعي الذي يشمل ابتكار أفكار جديدة.

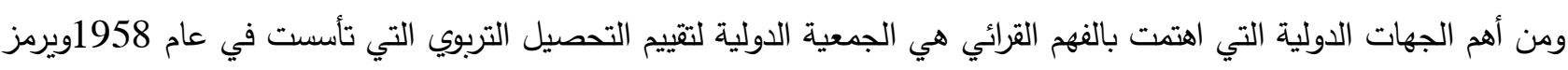

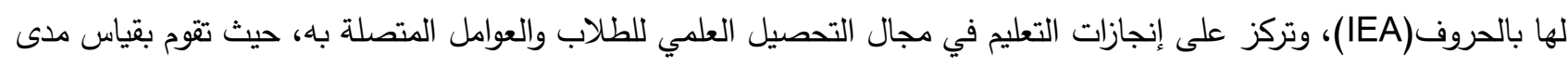
إتقان الطلاب لمواد الرياضيات، والعلوم، والقراءة؛ وتجري تقييمات بشأن التحصيل والتربية والمواطنة. ومن أهدافها مساعدة فئن

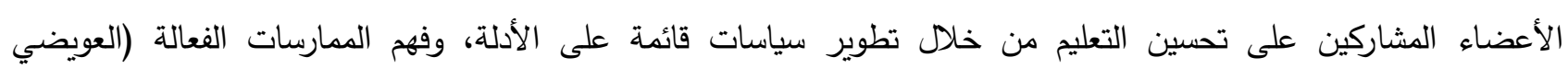
والقحطاني 1441، 1461) وتثـارك أكثر من 40 دولة في دراسة تتمية المقدرة القرائية بيرلز (Pirls) مع اختلاف مستوياتهم الاقتصـادية واختلاف ثقافاتهم

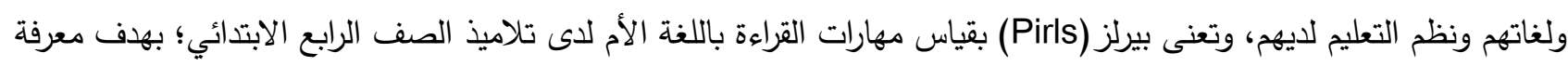

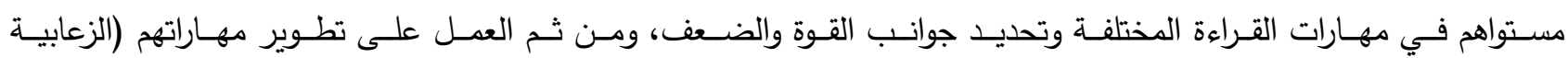


وتستتد " بيرلز " (Pirls) إلى إطار شامل يستدعي التأكد من مدى فهم الطلاب لعدد كبير من النصوص المتتوعة لهدفين هما:

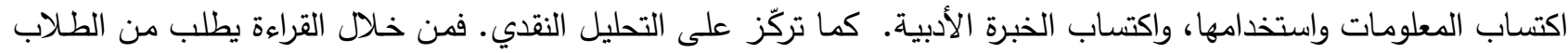

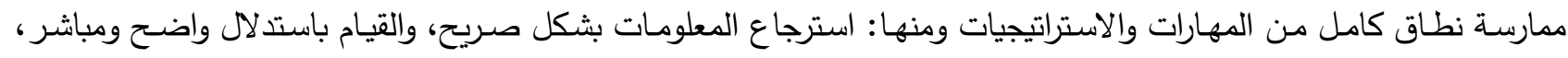

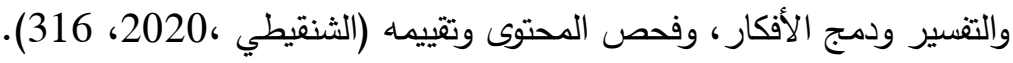
ويتكون اختبار بيرلز (Pirls) من نصين يناسبان مستوى طلاب الصف الرابع الابتدائي الأول علمي وهو نص معلوماتي، والثاني أدبي يكون قصة أو حكاية واقعية. وعلى الطلاب قراءة كلا النصين والإجابة عن أسئلتهما، ويمنح الطلاب 80 دقيقة (مدة الأبناب الاختبار) للقراءة والإجابة عن أسئلة النصين. متاح عبر وائه والرابط: (https://heefa.net/files/PIRLS2011_Framework.pdf)

وتتفق مستويات الكفاية القرائية في دراسة بيرلز (Pirls) مع مستويات الفهم القرائي المرتبطة بعمليات التفكير وهي : عملية التحديد التي تتطلب استدعاء معلومات مذكورة في المقروء ،وعملية التحليل التي يتم فيها استتباط معلومات من النص القرائي ،ثم عملية التقويم التي يقوم فيها القارئ بالحكم على المعلومات والبيانات في المقروء في ضوه مؤشرات محددة ، وأخيرا عملية التطبيق التي

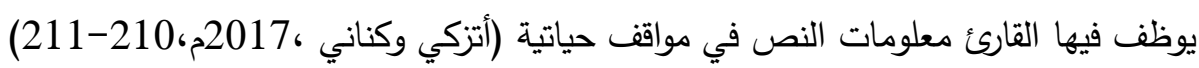
كما تعمل دراسة بيرلز (Pirls) على تحليل النظم الددرسية، فيتم جمع البيانات من استبيانات موجهة لمديري المدارس والمعلمين

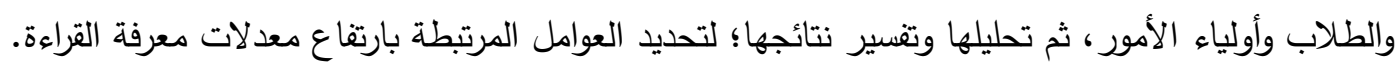

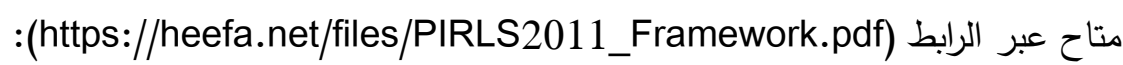
وقد عنيت دراسة بيرلز بفحص أداء المعلمين ودراسة كافة العوامل المؤثرة في مقدرتهم على تتمية القراءة، حيث إن دراسة معايير

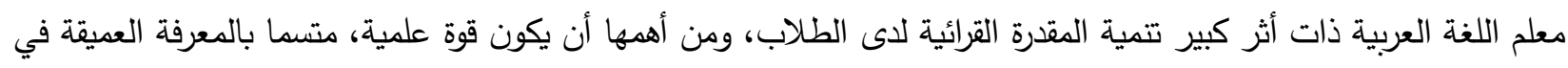

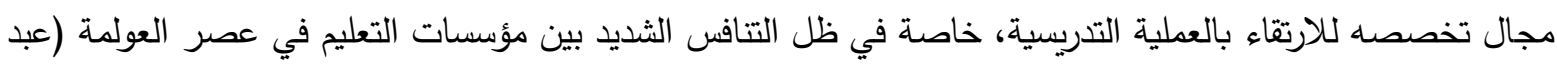

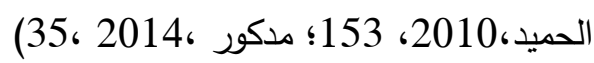

كما أثارت البحوث التربوية المتعلقة بدراسات بيرلز إلى أن مهارات المعلم التدريسية ، وقدرته على تطوير كفاياته وخاصة ما

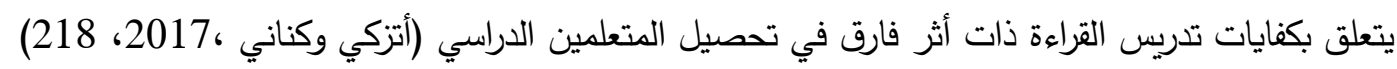

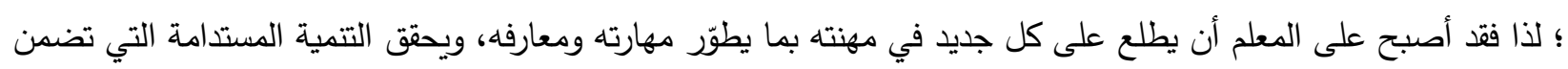

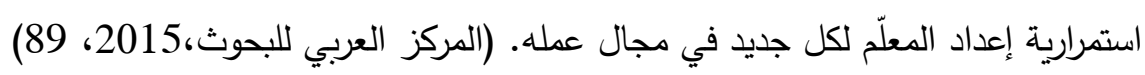
1 يجمع التربويون على أهمية مهارات الفهم القرائي، إلا أن نتائج بعض الدراسات العربية أشارت إلى ضعف ألى أداء معظم المعلمين المرتبط بتتمية مهارات الفهم القرائي لاى الطلاب، وربما يرجع ذلك إلى عدم معرفة هؤلاء المعلمين بالمهارات، أو عدم وعيهم بها،

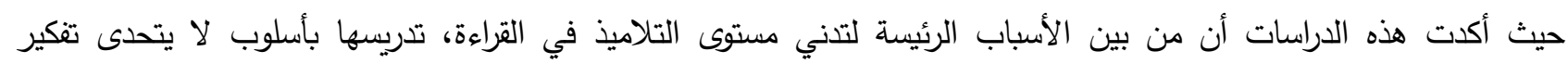

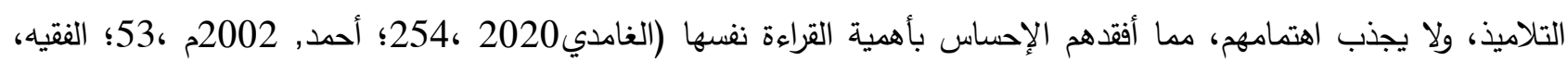
. 129 2003 وفي المملكة العربية السعودية كثفت نتائج مشاركة المملكة العربية السعودية في اختبار القراءة الدولي "بيرلز" عام 2011م، عن أن الطلاب لا يجيدون الاستدلال المباشر حول السمات الأساسية للشخصيات ودوافعها ومشاعرها، ولا يستطيعون تفسير الأحداث

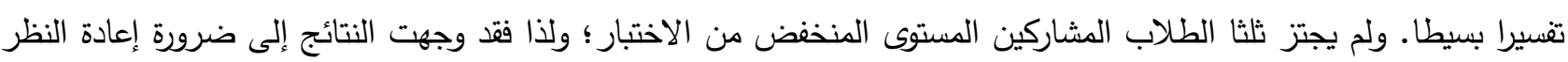
في ممارسات تدريس القراءة ومدى الاهتمام بالفهم القرائي الذي يربط خبرات الطلاب بمعنى المقروء. 
وفي دراسة الثنقيطي (2020) التي تتبعت فاعلية برنامج تدريبي في توعية معلمات اللغة العربية بالممارسات المثلى لرفع المقدرة

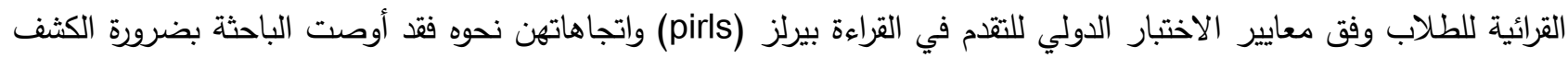
عن الممارسات التدريسية للمعلمين والتي يمكن ربطها بنتائج الاختبارات الدولية.

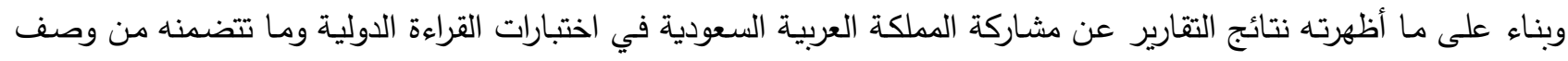
لتدني مستوى طلابنا وطالباتتا مقارنة بأقرانهم في العالم، وما أكدته نتائج البحوث واتئاء والدراسات من أثر المعلم في تحصيل المتعلمين

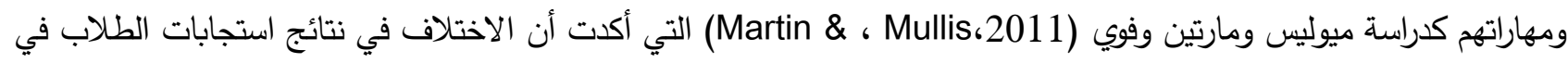
اختبار بيرلز عائد إلى الاختلاف في المناهج الدراسية وطرق التدريس التي يعتمدها المعلمون، والمنعكسة على مستويات القراءة

لديهم.

فقد تبلورت مشكلة الدراسة في السؤال الرئيس التالي:

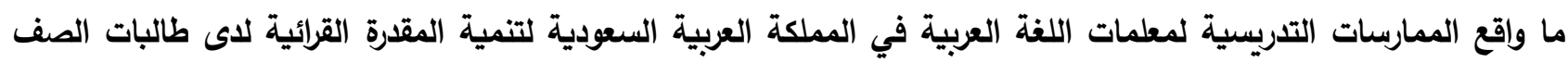
الرابع الابتدائي وفق مؤشرات اختبار بيرلز؟ وينبثق من هذا السؤال الرئيس الأسئلة الفرعية التالية:

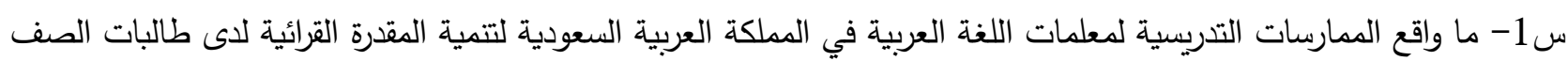
الرابع الابتدائي وفق مؤشرات اختبار بيرلز في المستويات من 1 إلى 4؟ س2-هل هناك علاقة ذات دلالة إحصائية بين المستويات في واقع الممارسات التدريسية لمعلمات اللغة العربية في المملكة العربية السعودية لتتمية المقدرة القرائية للى طالبات الصف الرابع الابتدائي وفق مؤشرات اختبار بيرلز ؟ س-3-هل هناك فروق ذات دلالة إحصائية في الممارسات التدريسية لمعلمات اللغة العربية في المملكة العربية السعودية لتمية لئية المقدرة القرائية لاى طالبات الصف الرابع الابتدائي وفق مؤشرات اختبار بيرلز تعزى إلى بعض المتغيرات (المدينة، المعرفة باختبار بيرلز ، ووسيلتها) 2- 2 أهمية الدراسة: يمكن إبراز أهمية الدراسة الحالية من خلال ما يلي: أ- الأهمية النظرية: تواكب هذه الدراسة ما تتطلع إليه وزارة التعليم في المملكة العربية السعودية في إحراز نتائج متقدمة في المسابقات الدولية والاختبارات المعيارية. ب-الأهمية التطبيقية: إن الأهمية التطبيقية لهذه الدراسة تتمثل في كونها دراسة جديدة في مجالها، وتساعد في الكثف عن ممارسات المعلمين المحققة لنتائج متقدمة لطلابهم في الاختبارات الدولية المعيارية. 3- حدود الدراسة: أُجريت الدراسة الحالية وفقًا للحدود الآتية: الحد المكاني: المملكة العربية السعودية، تتاولت معلمات المرحلة الابتدائية في ثلاث مدن في المملكة العربية السعودية وهي :مدينة الرياض، ومدينة جدة ،ومدينة عرعر. الحد الزمني: 1441هـ الفصل الدراسي الثاني. الحد الموضوعي: تقتصر الدراسة الحالية على الكثف عن ممارسات معلمات اللغة العربية في تدريس مقرر القراءة وفق مستويات اختبار بيرلز (Pirls).

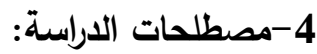
الممارسة لغة: من " مارس" الثَّخصُ الثَّيءَ، وذلك إذا عالجه وزاوله، قام بعمله باستمرار. 
الممارسة اصطلاحا: هي نوع من الخبرة المنظمة نسبيا، تتضمن معنى تكرار الاستجابات في مواقف مشابهة .(علي ، 2011

التدريس لغة : من درَّس الكتابَ ونحوَه :أي قام بتدريسه، بأن أقرأه وأفهمه للطَّلاب . التدريس اصطلاحا: هو العملية التي تتولى تعليم المنهج للطلاب وتعلمه ؛من خلال عمليات فرعية متسلسلة ثلاثة هي : التخطيط ثم التنفيذ ، ثم التقويم .(علي ، 2011، 91) وتعرف الممارسة التدريسية إجرائيا بأنها: بأنها العمليات التي تقوم بها معلمات اللغة العربية في أثناء التخطيط والتنفيذ والتقويم لتعليم مقرر لغتي؛ بهدف رفع المقدرة القرائية لاى الطالبات وفق معايير الاختبار الدولي للتقدم في القراءة بيرلز (Pirls).

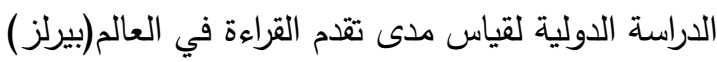

Progress in International Reading Literacy Study (pirls) هي دراسة دولية تشرف عليها الجمعية الدولية لتقييم التحصيل التربوي(iea) ، تهدف إلى بناء معايير ومحكات من أجل المقارنة بين الدول المشاركة في تقييم قدرة طلاب الصف الرابع في مهارات القراءة بلغتهم الأم، وتقيس قدرة القراء الصغار على فهم

واستخدام أشكال لغوية متتوعة(Lenkeit et al,2017).

5: الاراسات السابقة ذات الصلة:

إن الباحث في الدراسات والبحوث العربية ذات العلاقة بالاختبارات الدولية في القراءة يجد ندرة كبيرة، بينما اهتمت بعض مراكز

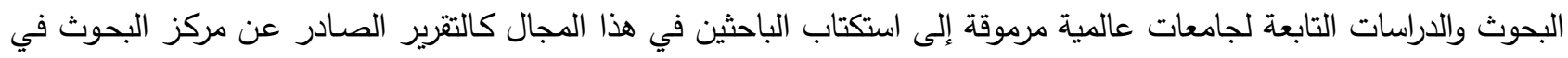
جامعة بوسطن والآخر الصادر عن اكسفورد. في الدراسات العربية فنجد دراسة أمامة الشنقيطي (2020) التي طبقت على عينة بلغ عددها (64) معلمة للغة العربية في منطقة الرياض؛ بهدف الكثف عنف عن فاعلية برنامج تدريبي في توعية معلّمات اللغة العربية

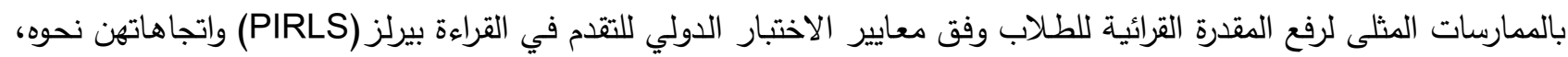

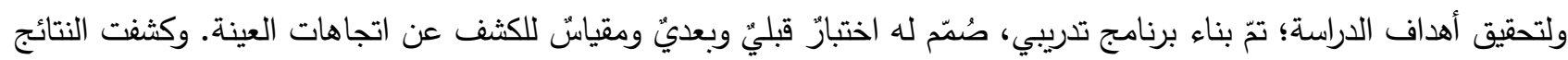

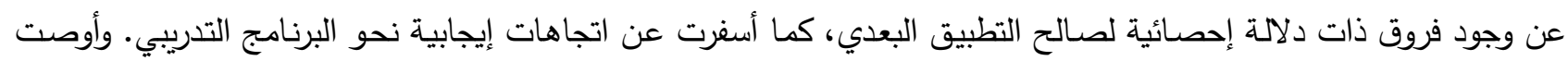

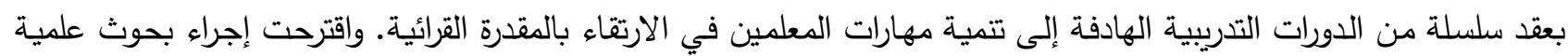

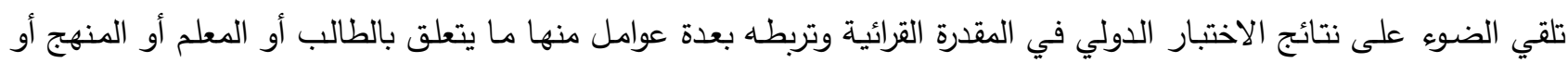
الأسرة والمجتمع. كما أجرت أمل الزعابية والمحرزي (2019) دراسة مشتركة هدفت إلى معايرة بيانات سلطنة عمان في كتيبات اختبار (PIRLS)

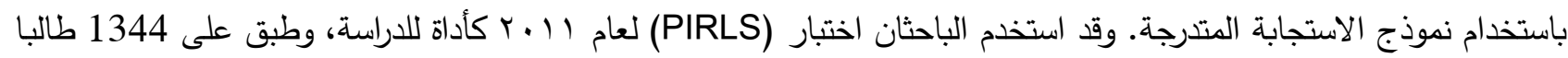
وطالبة من طلاب الصف الرابع الأساسي بسلطنة عمان. حيث تم التحقق من افتراضات نظرية الاستجابة للمفردة. وأسفرت النتائج عن تحقق افتراضات نموذج الاستجابة المتدرجة. وفي عام (2017) نشر أتزكي وكناني دراسة تهدف إلى توصيف المردودية القرائية للمتعلمين المغاربة في ضوء نتائج نتائج دراسة بيرلز 2011 من خلال رصد محتوياتها ، مناقثة مرجعيات تقويمات بيرلز المعرفية، ومناقشة العوامل المؤثرة في النتائج على المتعلقة بالأسرة والمعلم والبيئة المدرسية المغربية ، ثم مناقثة سبل اسثمار نتائجها في تطوير الأداء القرائي للمتعلمين المغاربة.

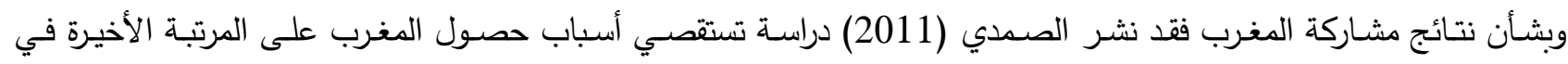
التصنيف الدولي في اختبار PIRLS PIR، واستقصى تأثيرات كل من: البيئة، والأسرة، والمدرسة وتطبيقات المناهج في على 2011 الدقدرة القرائية، وأوصت الدراسـة القطاع التربوي بالانطلاق من النتائج في إعادة النظر بجدية في بناء استراتيجيات الفهم عند المتعلمين ، ومعالجة العوامل التي ساهدت في انحدار مؤشرات جودة التعليم في المغرب. 


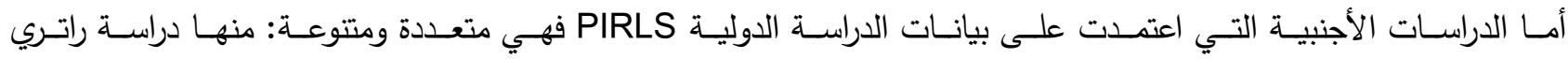
(Ratry,2015)، التي استخدمت بيانات اختبار PIRLS 2011 لطلاب دولة إندونيسيا بهدف الكثف عن تأثير اتجاهات الطالب داتبه والعوامل المحيطة به من: الممارسات القرائية داخل المنزل، و خارج المدرسة، وتفاعل استخدام التقنية الحديثة مع مهارات الفهم القرائي، وكثفت نتائج الدراسة عن وجود دلالة إحصائية التأثير للعوامل المحيطة بالطالب على مقدرته القرائية . وأما دراسة زيمرمان (Zimumierman 2014) فقد اعتمدت بيانات PIRLS2006 ؛ لإجراء مقارنة بين أداء المدارس ذات ذات الإنجاز المرتفع في وذات الإنجاز المنخفض، وكثفت عن وجود تباين بين طرائق التدريس المستخدمة في تدريس الفهم القرائي بين

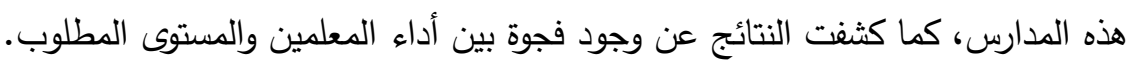
واستقصت دراسة أجراها كل من: فوي ومارتين وميوليس وستانكو (Stanco,2011 \& Mullis، Martin،Foy) الخصـائص

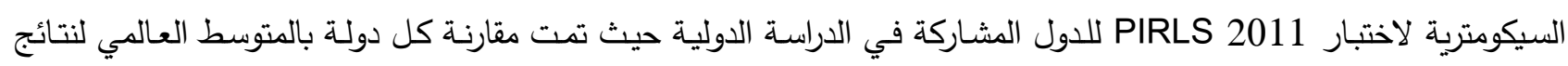
الاختبار في عام 2011، وذلك من خلال استجابات الطلاب على المفردات الثنائية والمتعددة الاستجابة. وأجرى ميوليس ومارتين وفوي (Martin \& Foy، Mullis،2011) دراسة عملت إلى الاستفادة من بيانات 34 دولة في اختبارات

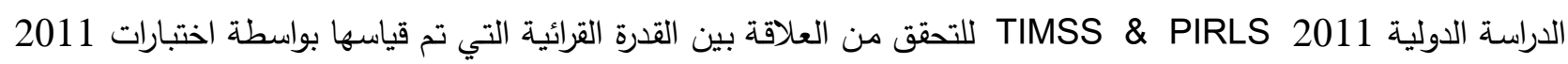
وكيفية تأثيرها على أداء طلاب الصف الرابع في فهم مسائل الرياضيات والعلوم في اختبارات TIRLS إلى التحقق من العلاقة بين المقدرة القرائية للى الطلاب والقدرة على الإجابة مستويات متدرجة الصعوبة من أسئلة اختبار هI وأكدت النتائج صحة فرضية الدراسة المتعلقة بأن الطلاب ذوي القدرة القرائية العالية في اختبار 2011 PIRSS الأفضل في الاستجابة على جميع مفردات اختبار TIMSS بمختلف مستويات صعوبتها، وفسرت الدراسة هذا الاختلاف في نتائج استجابات الطلاب بأنه عائد إلى الاختلاف في المناهج الدراسية وطرق التدريس التي يعتمدها المعلمون، والمنعكسة على مستويات القراءة لديهم. وفي مجال ممارسات معلمي اللغة العربية التدريسية فقد أجرى الفرا (2018) دراسة هدفت إلى الكثف عن درجة أهمية وممارسة

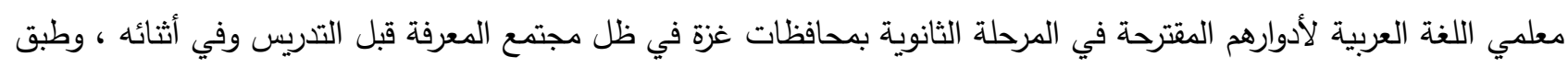

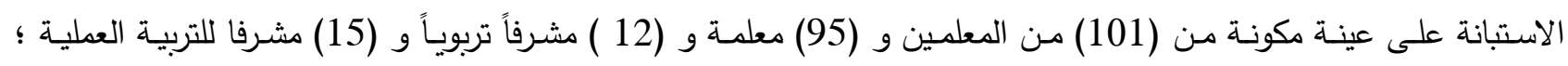

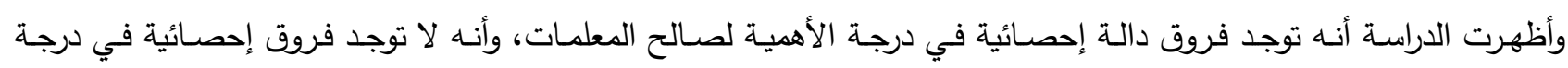
الممارسة بين المعلمين والمعلمات، مما يدل على وعي المعلمين بأدوارهم ،وتطوير ممارساتهم التدريسية. 6- 6 التعليق على الدراسات السابقة: 1- يتضـح دن خـلال عرض الدراسـات السـابقة أنها اتسمت بالتتوع في مجتمـع الدراسـة، ممـا يوضـح إمكانية وتعميم نتائجها، والدراسة الحالية تتفق في الفئة المستهدفة مـع دراسـة الثنقيطي (2020) ودراسـة الفرا (2018) التي طبقت على معلمي اللغة العربية. 2- اتققت الدراسة الحالية مـع دراسة الفرا (2018) في اعتمادها على المنهج الوصفي، وندرت الدراسات التي انتهجت المنهج التجريبي كدراسة الثنقيطي 2020. 3- أكدت نتائج الدراسات السابقة كدراسة الثنقيطي (2020) ودراسة الفرا (2018) ودراسة أتزكي وكناني (2017) والصمدي (2014) الحاجة إلى تطوير مهارات المعلمين في مجال مهارات اختبار بيرلز ، مما يعني اتفاقها مع الدّرّاسة الحالية في الهدف.

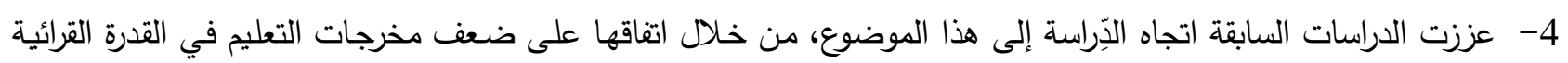

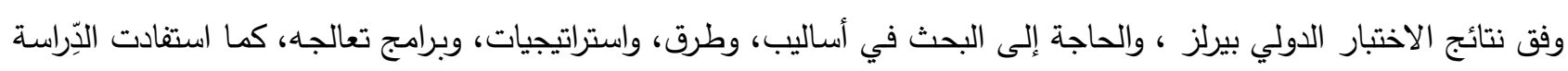
الحالية من تلك الدراسات في جوانبها كافة؛ فأسهمت تلك الداني الدراسات في إثراء الإطار النظري للدراسة الحالية، وفي تعرف المراجع 
والمصادر العلمية المناسبة، التي يمكن الاستفادة منها في الإطار النظري، أو في مناقشة النتائج، كما تمت الاستفادة من هذه

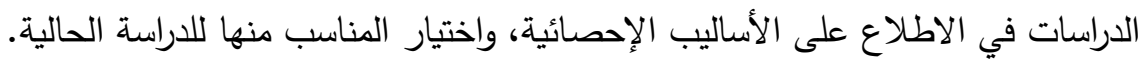

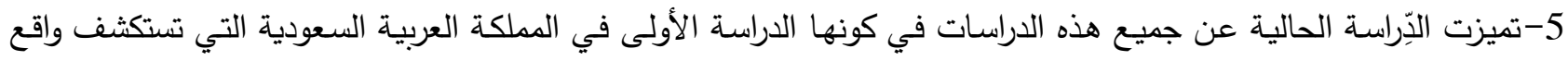
ممارسا معلمات اللغة العربية التدريسية لتتمية المقدرة القرائية وفق مؤشرات بيرلز .

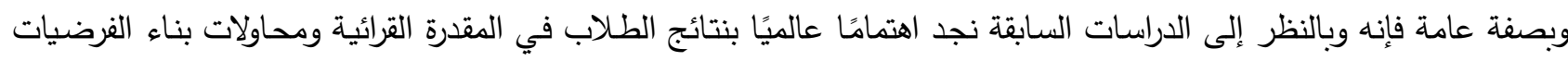
التي تربطه بعوامل عديدة، بينما نلمس شح الدراسات العربية في هذا المجال (https://timssandpirls.bc.edu/pirls2016/downloads/P16_Framework_2ndEd.pdf5) ويعكس هذا الاهتمام باختبار بيرلز (Pirls)العناية بتعلم القراءة؛ لكون العلاقة بين التحصيل وتمكن الطلاب من مهارات القراءة علاقة تكاملية، ونظرا لكونها من أهم مداخل التربية لإمداد الطلاب بالألفاظ والتراكيب، وتتمية ثروة التلاميذ اللغوية، ومساعدتهر

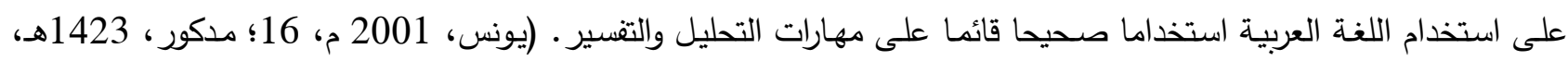

ثانياً: إجراءات الاراسة الميدانية.

\section{1-منهج الاراسة:}

لتحقيق أهداف الدراسة تم استخدام المنهج البحثي الملائم لطبيعة الدراسة وأهدافها، وقد استخدمت الباحثة في ذلك المنهج

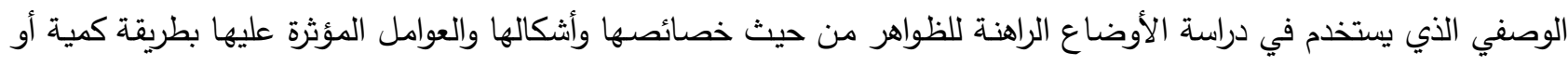

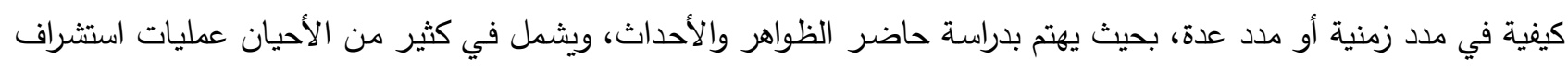
(تتبؤ) لمستقبل الظواهر والأحداث التي يدرسها. 2-مجتمع الاراسة: يتمثل مجتمع الدراسة الحالية في جميع معلمي ومعلمات اللغة العربية المرحلة الابتدائية في مدن (الرياض، واضيكا. وجدة، وعرعر) في المملكة العربية السعودية، وقد بلغ عددهم في هذه المدن (90700) معلما، في الفصل الدراسي الثاني للعام

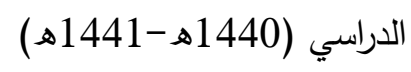
3-عينة الاراسة:

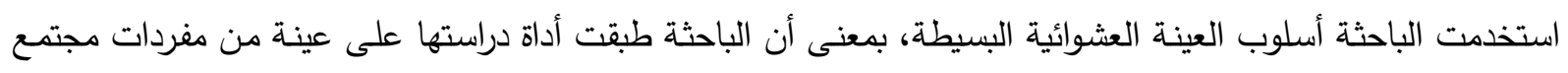

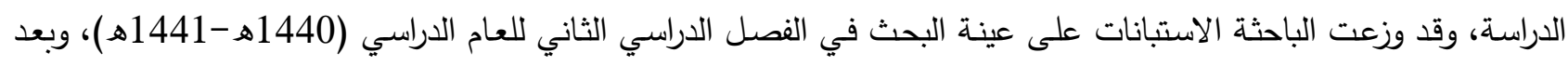
التطبيق الميداني حصلت الباحثة على (400) استبانة صالحة للتحليل الإحصائي.

خصائص مفردات الاراسة وعينتها:

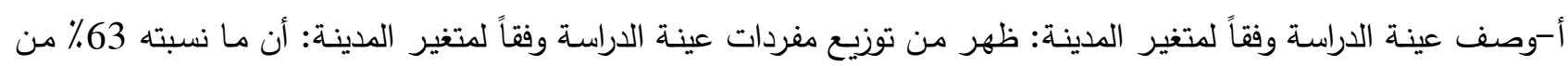

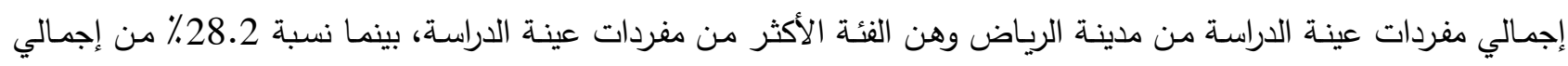
مفردات عينة الدراسة من مدينة جدة، مقابل ما نسبته 8.8٪ من إجمالي مفردات عينة الدراسة من مدينة عرعر .

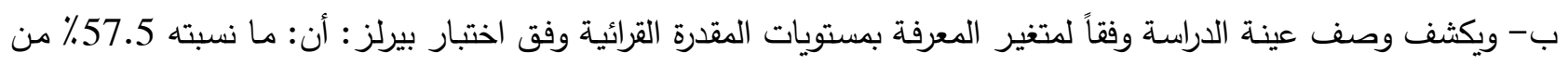
إجمالي مفردات عينة الدراسة لديهن معرفة واطلاع بمستويات المقدرة القرائية وفق اختبار بيرلز وهن الفئة الأكثر من مفردات عينة الدراسة، في حين أن نسبة 42.5٪ من إجمالي مفردات عينة الدراسة ليس لديهن معلومات عن الاختبار الدولي بيرلز .

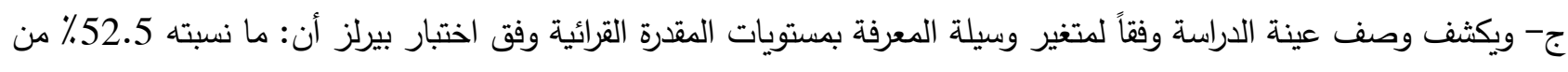
إجمالي مفردات عينة الدراسة معرفتهن بمستويات المقدرة القرائية وفق اختبار بيرلز من خلال جهود الإشراف التربوي والمدرسة وهن الفئة الأكثر من مفردات عينة الدراسة، بينما نسبة 30٪ من إجمالي مفردات عينة معرفتهن بمستويات المقدرة القرائية وفق اختبار 
بيرلز من خلال التعاميم والمنشورات الرسمية من وزارة التعليم، وأن 17.5٪ من إجمالي مفردات عينة الدراسة تعرفن على مستويات المقدرة القرائية وفق اختبار بيرلز من خلال دورات تدريبية في الاختبارات الدولية. 4-أداة الدراسة وإجراءات بنائها: يقصد بأداة البحث: الوسيلة التي تتم بوسـاطتها عمليـة جمـع البيانـات بهدف اختبار فرضيات البحث أو الإجابة عن

اعتمـدت الدراسـة على الاسـتبانة؛ للتعـرف على واقع ممارسـات معلمـات اللغـة العربيـة التدريسية في المملكة العربيـة

السعودية لتتمية المقدرة القرائية للطالبات وفق مؤشرات اختبار بيرلز الناسئ

وقد تكونت الاستبانة في صورتها النهائية من قسمين: القسم الأول: البيانات الأولية: التي تتعلق بالمتغيرات المستقلة، والتي تتضمن

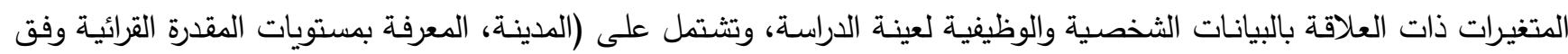
اختبار بيرلز ، وسيلة المعرفة بمستويات المقدرة القرائية وفق اختبار بيرلز ). أما القسم الثاني من الاستبانة: فثمل مستويات أدئه أداء قياس

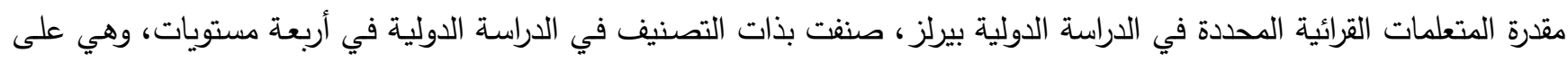
النحو الآتي: المحور الأول: الممارسات التدريسية في مستوى الأداء الأول، وتحتوي على عبارتين تمثلان عتبة المعيار الدولي الأدنى

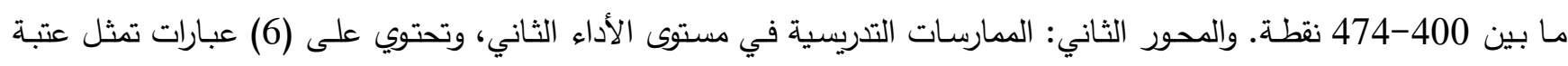
المعيار الدولي الأوسط ما بين 475-549. في حين احتوى المحور الثالث على (8) عبارات تمثل الممارسات التدريسية في مستوى ولئ

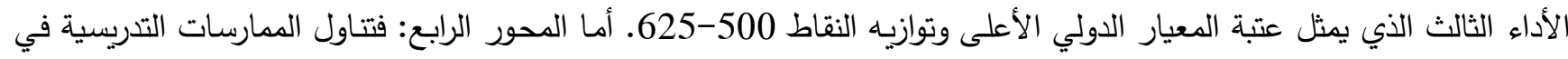

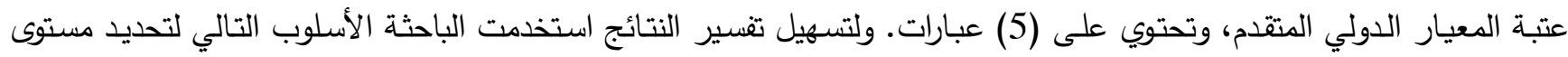

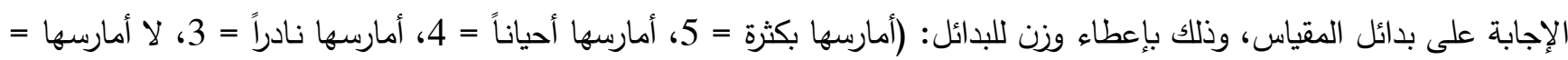
2، لا أمارسها إطلاقاً =1)، ثم صنفت الباحثة تلك الإجابات إلى خمس مستويات متساوية المدى عن طريق المعادلة الآتية:

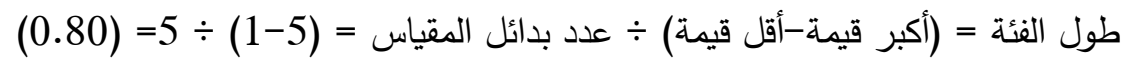
5-الخصائص السيكو متربية لأداة الاراسة: أ-صدق أداة الدراسةة:

(External Validity): الصدق الظاهري للأداة: للتعرف على مدى صدق أداة الدراسـة في قياس ما وضعت لقياسـه قامت الباحثة بعرضـها على مجموعة من المحكمين والخبراء من ذوي الخبرة والاختصاص، وفي ضوء تلك الملحوظات عدلت الباحثة، ثم قامت بكتابة الاستبانة في صورتها النهائية التي طبقت بها.

صدق الاتساق الداخلي: (Consistently Validity Internal) بعد التأكد من الصدق الظاهري لأداة الدراسة قامت الباحثة بتطبيقها ميدانياً، ثم قامت الباحثة بحساب معامل الارتباط بيرسون لمعرفة الصدق الداخلي للاستبانة حيث تم حساب معامل الارتباط بين درجة كل عبارة من عبارات الاستبانة بالدرجة الكلية للمحور لإدال الذي تتتمي إليه العبارة كما توضح ذلك الجداول التالية:

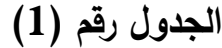




\section{معاملات ارتباط بيرسون لعبارات الممارسات التدريسية في المستويات من 1- 4}

\begin{tabular}{|c|c|c|}
\hline معامل الارتباط & رقم العبارة & المستوى \\
\hline$* * 0.834$ & 1 & \multirow{2}{*}{ الممارسات التدريسية في المستوى الأول } \\
\hline **0 0.908 & 2 & \\
\hline ***0.576 & 3 & \multirow{6}{*}{ الممارسات التدريسية في المستوى الأول } \\
\hline **0.740 & 4 & \\
\hline$* * 0.450$ & 5 & \\
\hline$* * 0.834$ & 6 & \\
\hline **0.804 & 7 & \\
\hline$* * 0.846$ & 8 & \\
\hline$* * 0.766$ & 9 & \multirow{8}{*}{ الممارسات التدريسية في المستوى الثالث } \\
\hline$* * 0.830$ & 10 & \\
\hline$* * 0.828$ & 11 & \\
\hline$* * 0.816$ & 12 & \\
\hline **0.858 & 13 & \\
\hline$* * 0.680$ & 14 & \\
\hline$* * 0.842$ & 15 & \\
\hline$* * 0.851$ & 16 & \\
\hline$* * 0.947$ & 17 & \multirow{5}{*}{ الممارسات التتريسية في المستوى الرابع بيع لعبارات } \\
\hline ***0.834 & 18 & \\
\hline ***0.845 & 19 & \\
\hline$* * 0.917$ & 20 & \\
\hline$* * 0.874$ & 21 & \\
\hline
\end{tabular}

*** دال عند مستوى الدلالة 0.01 فأقل

يتضح من الجدول(1) أن قيم معامل ارتباط كل عبارة من العبارات مع المستوى الذي تتنمي له موجبة ودالة إحصائياً عند مستوى

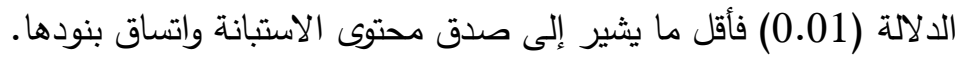

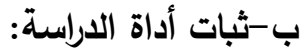
لقياس مدى ثبات أداة الدراسة (الاستبانة) استخدمت الباحثة (معادلة ألفا كرونباخ)؛ للتأكد من ثبات أداة الدراسة.

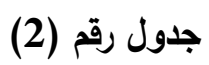

معامل ألفا كرونباخ لقياس ثبات أداة الدراسة

\begin{tabular}{|c|c|c|}
\hline ثبات المحور & عدد العبارات & محساور الاستبانة \\
\hline 0.773 & 2 & الممارسات التدريسية في المستوى الأول \\
\hline 0.813 & 6 & الممارسات التدريسية في المستوى الثاني \\
\hline 0.911 & 8 & الممارسات التدريسية في المستوى الثالث \\
\hline
\end{tabular}




\begin{tabular}{|c|c|c|}
\hline ثبات المحور & عدد العبارات & محساور الاستبانة \\
\hline 0.925 & 5 & الممارسات التدريسية في المستوى الرابع \\
\hline 0.960 & 21 & الثبات العام \\
\hline
\end{tabular}

يتضـح من الجدول رقم (2) أن قيم معاملات الثبات لأبعاد ومحساور الدراسـة يتراوح بين (0.77) و(0.93) وأن معامل الثبات العام للاستبانة عال حيث بلغ (0.96) وهذا يدل على أن الاستبانة تتمتع بدرجة عالية من الثبات يمكن الوثوق بها في التطبيق الميداني للدراسة. 6-الأساليب الإحصائية: لتحقيق أهداف الدراسة وتحليل البيانات التي جمعتها الباحثة، فقد استخدمت الباحثة عدداً من الأساليب الإحصائية المناسبة باستخدام برنامج (SPSS)، ثم استخرجت الباحثة النتائج وفاقاً للأساليب الإحصائية الآتية:

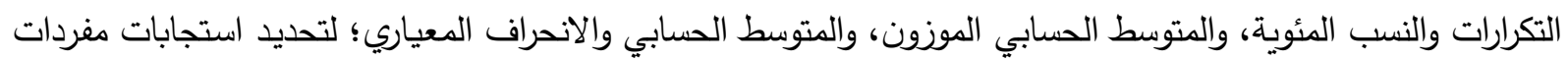

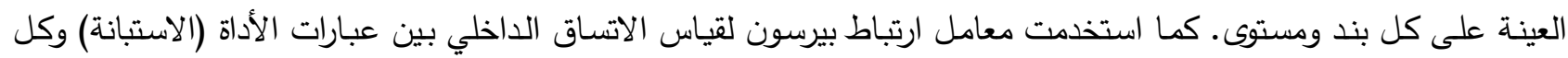

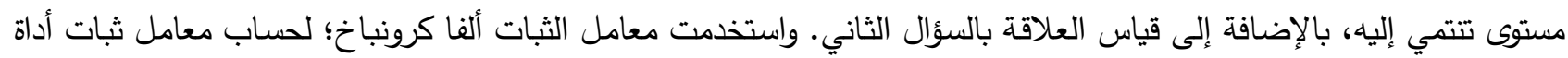
الدراسة. واختبار ت؛ لتوضيح دلالة الفروق في إجابات مفردات عينة الدراسة طبقاً إلى اختلاف متغيراتهم التي تتقسم إلى فئتين. واستخدمت تحليل التباين الأحادي؛ لتوضيح دلالة الفروق في إجابات مفردات عينة الدراسة طبقاً إلى اختلاف متغيراتهم التي تتقسم إلى أكثر من فئتين. واخيرا اختبار (أقل فرق معنوي) (LSD)، لتوضيح دلالة الفروق، في إجابات مفردات عينة الدراسة.

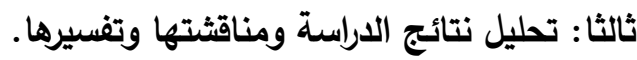
1-إجابة السؤال الأول: " مـا واقع الممارسـات التدريسية لمعلمات التهات اللفة العربية في المملكة العربية السعودية لتنمية المقدرة القرائية لاى طالبات الصف الرابع الابتدائي وفق مؤشرات اختبار بيرلز في المستويات من: 1 إلى 4" وللإجابة عن هذا السؤال قامت الباحثة بحساب المتوسطات الحسابية لمؤشرات اختبار بيرلز في المستويات من فئست : ( 1 إلى 4 ) )، وكذلك المتوسط الحسابي الكلي، وجاءت النتائج كما بالجدول الآتي: جدول رقم (3) جمان

المتوسطات الحسابية لمؤشرات اختبار بيرلز في المستويات من 1 إلى 4

\begin{tabular}{|c|c|c|c|c|}
\hline درجة الممارسة & 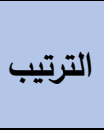 & 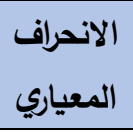 & المسابي & 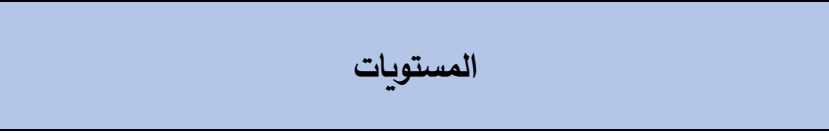 \\
\hline أمارسها بكثرة & 1 & 0.518 & 4.66 & الممارسات التدريسية في المستوى الأول \\
\hline أمارسها بكثرة & 2 & 0.480 & 4.60 & الممارسات التدريسية في المستوى الثاني \\
\hline أمارسها بكثرة & 4 & 0.603 & 4.51 & الممارسات التدريسية في المستوى الثالث \\
\hline أمارسها بكثرة & 3 & 0.689 & 4.58 & الممارسات التدريسية في المستوى الرابع \\
\hline \multicolumn{2}{|c|}{ أمارسها بكثرة } & 0.546 & 4.57 & 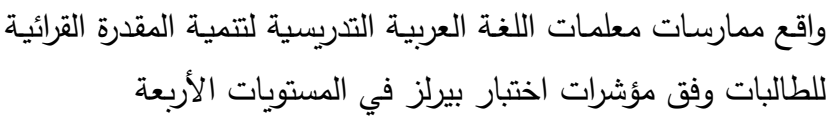 \\
\hline
\end{tabular}

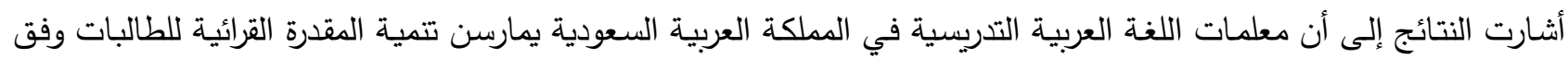
مؤشرات اختبار بيرلز في المستويات من : ( 1 إلى 4) بكثرة (4.57)، وأن هذا الأمر ظهر في جميع المستويات، وجاء أكثرها

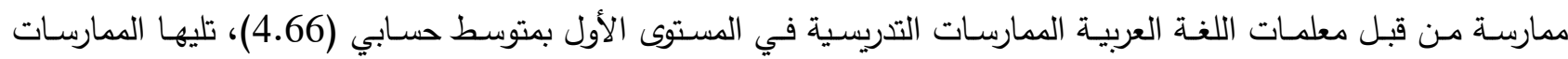
التدريسية في المستوى الثاني بمتوسط حسابي (4.60)، ثم الممارسات التدريسية في المستوى الرابع بمتوسط حسابي (4.58)، وأخيراً الممارسات التدريسية في المستوى الثالث بمتوسط حسابي (4.51). وتتفق هذه النتيجة مع نتائج طلاب المملكة العربية 
السعودية المعلنة من وزارة التعليم 2017، المتضمنة في ورقة عمل نشرها فريق بحثي من وكالة وزارة التعليم للبنين، والتي كثفت

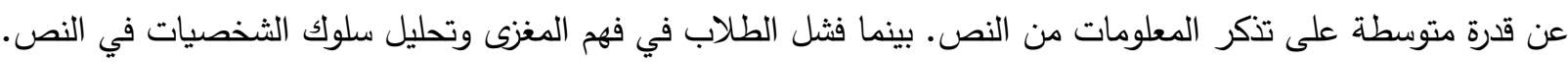
وتم حسـاب التكرارات، والنسـب المئويـة، والمتوسطات الحسـابية، والانحرافات المعياريـة، والرتب لدرجـة ممارسـات معلمـات اللغـة العربية التدريسية في المملكة العربية السعودية لتنمية المقدرة القرائية للطالبات وفق مؤشرات اختبار بيرلز في المستويات من 1 إلى ولى

أ- الممارسات التدريسية في المستوى الأول:

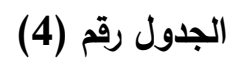

التكرارات والنسب المئوية والمتوسطات الحسابية والانحرافات المعيارية والترتيب لبنود الممارسات التدريسية في المستوى الأول $:(400=0)$

\begin{tabular}{|c|c|c|c|c|}
\hline 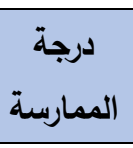 & الترتيب & 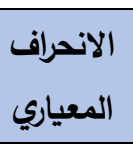 & المتوسط & نص العبارة \\
\hline 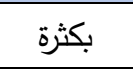 & الأولي & 0.511 & 4.80 & تحديد موقع واستذكار التفاصيل المذكورة أعلاه \\
\hline بكثرة & الثانية & 0.671 & 4.53 & في بدية موقع وإعادة صياغة المعلومات المعلنة صراحة التي تقع \\
\hline بكثرة & & 0.518 & 4.66 & المتوسط العام لبنود الممارسات التدريسية في المستوى الأول \\
\hline
\end{tabular}

يتضح من الجدول رقم (4) أن: مفردات عينة الدراسة موافق

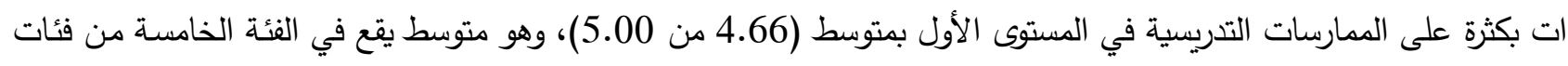
المقياس الخماسي (من 4.21 إلى 5.00)، وهي الفئة التي تثير إلى خيار "أمارسها بكثرة" في أداة الدراسة. ويتضح من النتائج أن: مفردات عينة الدراسة يمارسن بكثرة اثثين من الممارسات التدريسية في المستوى الأول تتمثل في العبارتين

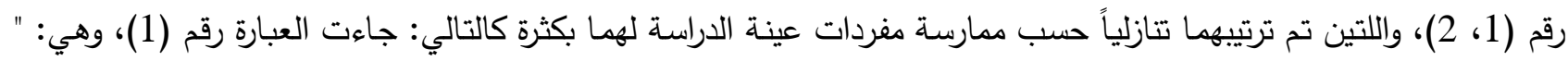
تحديد موقع واستخكار التفاصيل المذكورة أعلاه " بالمرتبة الأولى من حيث ممارسة مفردات عينة الدراسة لها بكثرة بمتوسط (4.80 من 5). ثم جاءت العبارة رقم (2)، وهي: " تحديد موقع وإعادة صياغة المعلومات المعلنة صراحة التي تقع في بداية النص "

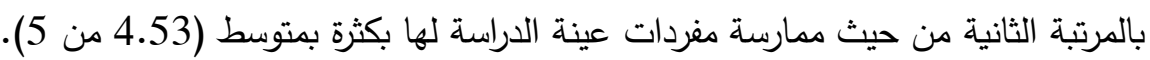
ب- الممارسات التدريسية في المستوى الثاني: بانيه

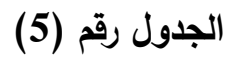

التكرارات والنسب المئوية والمتوسطات الحسابية والانحرافات المعيارية والترتيب لبنود الممارسات التدريسية في المستوى الثاني $:(400=\dot{0})$

\begin{tabular}{|c|c|c|c|c|c|}
\hline الممارسة & 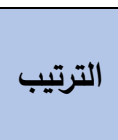 & الانحراف & الحستوسطي & 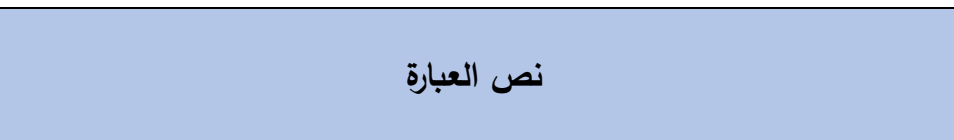 & قم \\
\hline 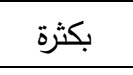 & 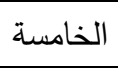 & 0.672 & 4.50 & استرداد وإعادة صياغة التصرفات والأحداث والمشاعر الصريحة & 3 \\
\hline بكثرة & 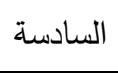 & 0.671 & 4.48 & القيام باستدلالات مباشرة حول سمات ومشاعر ودوافع الأشخاص الأساسية & 4 \\
\hline بكثرة & الأولي & 0.500 & 4.73 & تقديم تفسيرات بسيطة تشرح الأسباب & 5 \\
\hline 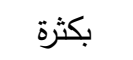 & الثانية & 0.708 & 4.73 & البدء بالتعرف على خصائص اللغة وأساليبها & 6 \\
\hline بكثرة & 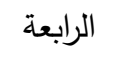 & 0.706 & 4.55 & تحديد موقع أو إعادة صياغة اثثين أو ثلاث من المعلومات المضمنة في النص & 7 \\
\hline
\end{tabular}

419 IUG Journal of Educational and Psychology Sciences (Islamic University of Gaza) / CC BY 4.0 


\begin{tabular}{|c|c|c|c|c|c|}
\hline الممارسة & الترتيب & المعياري & الحسابي & 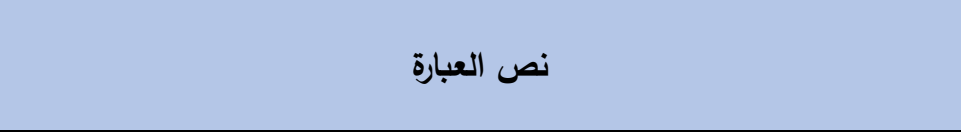 & ق ق \\
\hline 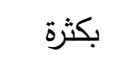 & 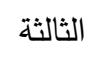 & 0.727 & 4.65 & استعمال العناوين الفرعية والمربعات النصية والرسوم التوضيحية للعثور على & 8 \\
\hline بكثرة & & 0.480 & 4.60 & المتوسط العام لبنود الممارسات التدريسية في المستوى الثاني & \\
\hline
\end{tabular}

يبين الجدول رقم (5) أن: العبارة رقم (5) والتي تنص على " تقديم تقسيرات بسيطة تشرح الأسباب " قد احتلت المرتبة الأولي بمتوسط حسابي (4.73) وانحراف معياري (0.50)، وجاءت العبارة رقم (6) والتي كان نصها " البدء بالتعرف على خصائص

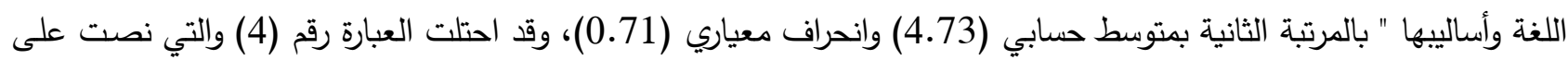
" القيام باستدلالات مباشرة حول سمات ومشاعر ودوافع الأشخاص الأساسية " المرتبة الأخيرة بمتوسط حسابي (4.48) وانحراف معياري (0.67)، وقد بلغ المتوسط الحسابي لاستجابات أفراد الدراسة على هذا المستوى ككل (4.60) بانحراف معياري (0.48) وهو يقابل تقدير الممارسة بكثرة على الممارسات التدريسية في المستوى الثاني. ج- الممارسات التدريسية في المستوى الثالث:

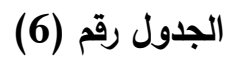

التكرارات والنسب المئوية والمتوسطات الحسابية والانحرافات المعيارية والترتيب لبنود الممارسات التدريسية في المستوى الثالث $:(400=0)$

\begin{tabular}{|c|c|c|c|c|c|}
\hline الممارسة & 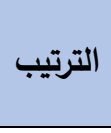 & 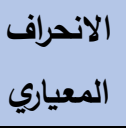 & المسابي & 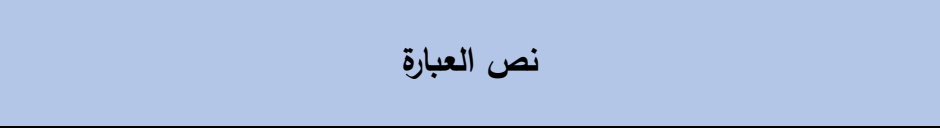 & 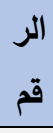 \\
\hline بكثرة & 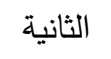 & 0.557 & 4.70 & تحديد وتمييز الأحداث المهمة والتفاصيل المضمنة داخل النص & 9 \\
\hline بكثرة & 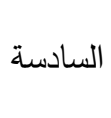 & 0.667 & 4.58 & تفسير وشرح العلاقات بين النوايا والتصرفات والأحداث والمشاعر ودعم ذلك & 10 \\
\hline بكثرة & الأولي & 0.570 & 4.78 & تفسير وربط أحداث القصة وتصرفات الأشخاص وصفاتهم من عدة مواضع & 11 \\
\hline بكثرة & 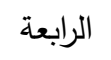 & 0.697 & 4.63 & تقييم أهمية الأحداث والتصرفات من خلال كامل القصة & 12 \\
\hline بكثرة & 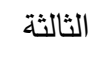 & 0.722 & 4.68 & التعرف على استخدام بعض الخصائص اللغوية مثل (الاستعارة ونبرت الصوت & 13 \\
\hline أحياناً & 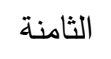 & 1.062 & 3.97 & تحديد موقع وتمييز المعلومات ذات الصلة ضمن نص مكثف أو جدول معقد & 14 \\
\hline 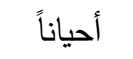 & 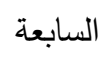 & 0.964 & 4.15 & يقوم بعمل استدلالات حول الصلات المنطقية لتقديم التفسيرات والأسباب & 15 \\
\hline 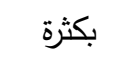 & 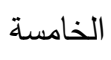 & 0.765 & 4.63 & ربط المعلومات النصية والمرئية لتفسير العلاقة بين الأفكار & 16 \\
\hline 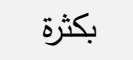 & & 0.603 & 4.51 & المتوسط العام لبنود الممارسات التدريسية في المستوى الثالث & \\
\hline
\end{tabular}

يبين الجدول رقم (6) أن: العبارة رقم (11) والتي تتص على " تفسير وربط أحداث القصة وتصرفات الأشخاص وصفاتهم من عدة

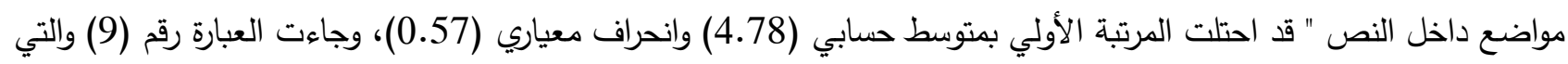
كان نصها " تحديد وتمييز الأحداث المهمة والتفاصيل المضمنة داخل النص " بالمرتبة الثانية بمتوسط حسابي (4.70) وانحراف

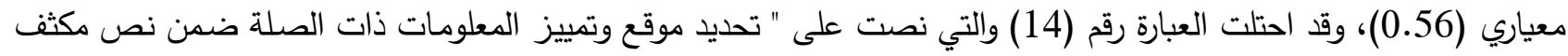
أو جدول معقد " المرتبة الأخيرة بمتوسط حسابي (3.97) وانحراف معياري (1.06)، وقد بلغ المتوسط الحسابي لاستجابات أفراد 
الدراسة على هذا المستوى ككل (4.51) بانحراف معياري (0.60) وهو يقابل تقدير الممارسة بكثرة على الممارسات التدريسية في

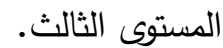

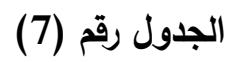

التكرارات والنسب المئوية والمتوسطات الحسابية والانحرافات المعيارية والترتيب لبنود الممارسات التدريسية في المستوى الرابع $:(400=\dot{0})$

\begin{tabular}{|c|c|c|c|c|c|}
\hline 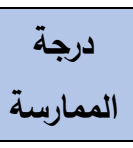 & الترتيب & 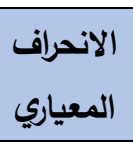 & المتوسط & 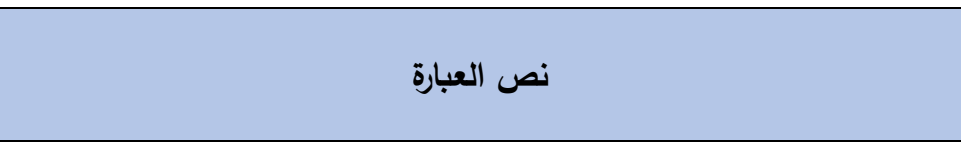 & 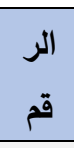 \\
\hline 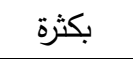 & الأولي & 0.699 & 4.75 & ربط الأفكار والأدلة عبر النص لفهم الموضوعات العامة & 17 \\
\hline 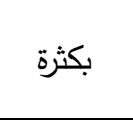 & 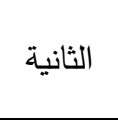 & 0.722 & 4.68 & توالسمات الثخدير أحداث القصـة وتصرفات الأثخاص لتقديم الأسباب والدوافع والمشـاعر & 18 \\
\hline 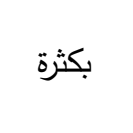 & 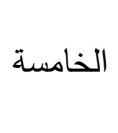 & 0.918 & 4.40 & تمييز وتفسير المعلومات المعقدة والمكونـة من أجزاء مختلفة وتقديم الاستـلال & 19 \\
\hline 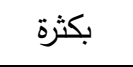 & 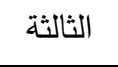 & 0.765 & 4.63 & ربط المعلومات عبر النص لإيجاد تفسيرات وتوضيح الأهمية وتسلسل الأنثطة & 20 \\
\hline 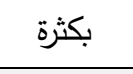 & 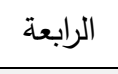 & 0.806 & 4.45 & تقديم الميزات البصرية والنصية وشرح وظائفها & 21 \\
\hline 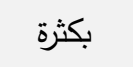 & & 0.689 & 4.58 & المتوسط العام لبنود الممارسات التدريسية في المستوى الرابع & \\
\hline
\end{tabular}

يبين الجدول رقم (7) أن: العبارة رقم (17) والتي تنص على " ربط الأفكار والأدلة عبر النص لفهم الموضوعات العامة " قد

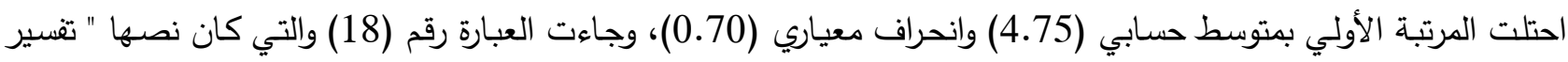
أحداث القصـة وتصـرفات الأشخاص لتقديم الأسباب والدوافع والمشـاعر والسمات الثخصية من خـلال النص الكامل " بالمرتبـة الثانيـة بمتوسط حسـبي (48.78) وانحراف معياري (0.72)، وقد احتلت العبارة رقم (19) والتي نصت على " تمييز وتقسير

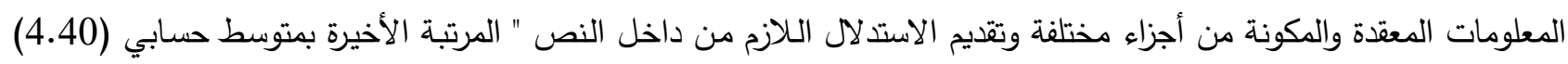

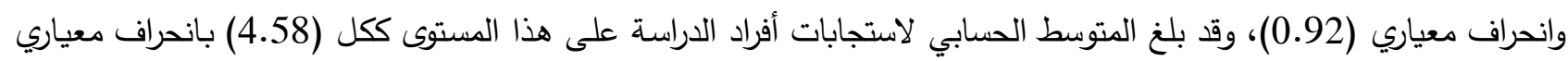
(0.48) وهو يقابل تقدير الممارسة بكثرة على الممارسات التدريسية في المستوى الرابع. 2-السؤال الثاني: "هل هناك علاقية ذائل ذات دلالة إحصائية بين المستويات في واقع الممارسات التدربسية لمعلمات اللغة العربية

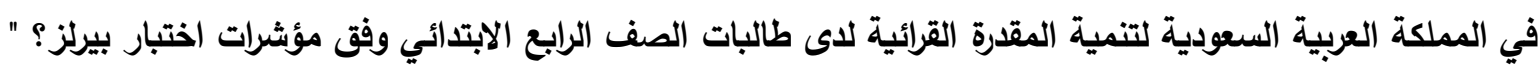
للتعرف على العلاقة بين المستويات في واقع ممارسات معلمات اللغة العربية التدريسية في المملكة العربية السعودية لتتمية المقدرة القرائية للطالبات وفق مؤشرات اختبار بيرلز تم استخدام معامل ارتباط بيرسون لتوضيح دلالة العلاقة بين هذه المتغيرات، وجاءت ولتهات النتائج كما يوضحها الجدول التالي: 


\section{جدول رقم (8)}

معاملات ارتباط بيرسون لتوضيح طبيعة العلاقة بين المستويات في واقع ممارسات معلمات اللغة العربية التدريسية في المملكة العربية السعودية لتنمية المقرة القرائية للطالبات وفق مؤشرات اختبار بيرلز لمئز

\begin{tabular}{|c|c|c|c|c|c|c|}
\hline جميع المستويات في التمارسات & التدريسية في الممارسات & التدريسية في الممارسات & التدربسية في المسارسات & $\begin{array}{l}\text { التدريسية في المستوى الأول } \\
\text { الميات }\end{array}$ & معامل بيرسون & المستويات \\
\hline$* * 0.688$ & $* * 0.543$ & $* * 0.650$ & $* * 0.637$ & & معامل الارتباط & \multirow{2}{*}{ 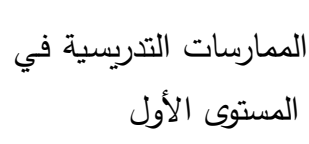 } \\
\hline 0.000 & 0.000 & 0.000 & 0.000 & & الدلالة الإحصائية & \\
\hline ***0.943 & ***0.857 & * * 0.893 & & * * 0.637 & معامل الارتباط & \multirow{2}{*}{ المستوى الثاني التدريسية في } \\
\hline 0.000 & 0.000 & 0.000 & & 0.000 & الدلالة الإحصائية & \\
\hline$* * 0.982$ & $* * 0.923$ & & $* * 0.893$ & $* * 0.650$ & معامل الارتباط & \multirow{2}{*}{ المستوى الثالث التدريسية في } \\
\hline 0.000 & 0.000 & & 0.000 & 0.000 & الدلالة الإحصائية & \\
\hline$* * 0.954$ & & $* * 0.923$ & $* * 0.857$ & $* * 0.543$ & معامل الارتباط & \multirow{2}{*}{ الممارسات التدريسية في } \\
\hline 0.000 & & 0.000 & 0.000 & 0.000 & الدلالة الإحصائية & \\
\hline & $* * 0.954$ & $* * 0.982$ & $* * 0.943$ & $* * 0.688$ & معامل الارتباط & \multirow{2}{*}{ الممارسات التدريسية في } \\
\hline & 0.000 & 0.000 & 0.000 & 0.000 & الدلالة الإحصائية & \\
\hline
\end{tabular}

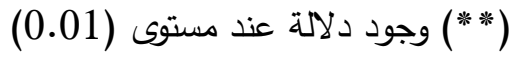

يتضح من النتائج الموضحة في الجدول رقم (8) وجود علاقة ارتباطية طردية دالة عند مستوى (0.01) بين المستويات في واقع ممارسات معلمات اللغة العربية التدريسية في المملكة العربية السعودية لتتمية المقدرة القرائية للطالبات وفق مؤشرات اختبار بيرلز . 3-السؤال الثالث: "هل هناك فروق ذات دلالة إحصائية في واقع ممارسات معلمات اللغة العربية التدريسية في المملكة العربية السعودية لتنمية المقدرة القرائية للطالبات وفق مؤشرات اختبار بيرلز تعزى إلى بعض المتغيرات (المدينة، المعرفة باختبار بيرلز،

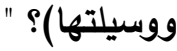

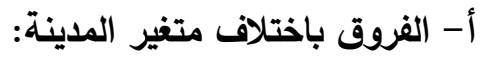

جدول رقم (9)

نتائج " تحليل التباين الأحادي " (One Way ANOVA) للفروق في إجابات مفردات عينة الدراسة طبقاً إلى اختلاف المدينة

\begin{tabular}{|c|c|c|c|c|c|c|}
\hline الإحصائية & قيمة ف & متوسط المربعات & الحربية & مجبعوع مربعات & مصدر التباين & المستويات \\
\hline \multirow{3}{*}{$* * 0.000$} & \multirow{3}{*}{42.589} & 9.445 & 2 & 18.891 & بين المجموعات & \multirow{3}{*}{ الممارسات التدريسية في } \\
\hline & & 0.222 & 397 & 88.047 & داخل & \\
\hline & & & 399 & 106.938 & المجموع & \\
\hline
\end{tabular}




\begin{tabular}{|c|c|c|c|c|c|c|}
\hline الإحصائية & قيمة ف & المربعات & الحرية & مجبعوع مربعات & مصدر التباين & المستويات \\
\hline \multirow{3}{*}{$* * 0.000$} & \multirow{3}{*}{21.566} & 4.510 & 2 & 9.021 & بين الدجموعات & \multirow{3}{*}{ الممارسات التدريسية في } \\
\hline & & 0.209 & 397 & 83.028 & داخل & \\
\hline & & & 399 & 92.049 & المجموع & \\
\hline \multirow{3}{*}{$* * 0.000$} & \multirow{3}{*}{25.515} & 8.272 & 2 & 16.544 & بين المجموعات & \multirow{3}{*}{ الممارسات التدريسية في } \\
\hline & & 0.324 & 397 & 128.706 & داخل & \\
\hline & & & 399 & 145.250 & المجموع & \\
\hline \multirow{3}{*}{$* * 0.000$} & \multirow{3}{*}{9.093} & 4.149 & 2 & 8.298 & بين المجموعات & \multirow{3}{*}{ الممارسات التدريسية في } \\
\hline & & 0.456 & 397 & 181.142 & داخل & \\
\hline & & & 399 & 189.440 & المجموع & \\
\hline \multirow{3}{*}{$* * 0.000$} & \multirow{3}{*}{22.711} & 6.097 & 2 & 12.194 & بين المجموعات & \multirow{3}{*}{ الممارسات التدريسية في جميع } \\
\hline & & 0.268 & 397 & 106.579 & داخل & \\
\hline & & & 399 & 118.773 & المجموع & \\
\hline
\end{tabular}

*2:دلالة إحصائية عند مستوى 0.05 فاقل

ويتضح من الجدول رقم (9): وجود فروق ذات دلالة إحصائية عند مستوى الدلالة الإحصائية (0.01) فأقل في إجابات مفردات عينة الدراسة حول (الممارسات التدريسية في المستوى الأول، الثاني، والثالث والرابع والممارسات التدريسية ككل) باختلاف متغير المدينة. وتم إجراء تحليل بعدي باستخدام اختبار أقل فرق معنوي " LSD "وجاءت النتائج كما يأتي: الجدول رقم (10) - (10)

"LSD " المقارنات البعدية على الممارسات التدريسية في المستوى الأول، الثاني، والثالث والرابع والممارسات التدريسية ككل للفروق بين المدن

\begin{tabular}{|c|c|c|c|c|c|}
\hline عرعر & 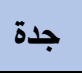 & 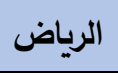 & المتوسط الحسابي & 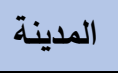 & المستويات \\
\hline$* *$ & $* *$ & - & 4.82 & 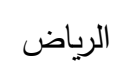 & \multirow{3}{*}{ الممارسات التدريسية في المستوى الأول } \\
\hline ** & - & & 4.45 & جدة & \\
\hline- & & & 4.20 & عرعر & \\
\hline ** & $* *$ & - & 4.71 & الرياض & \multirow{3}{*}{ الممارسات التدريسية في المستوى الثاني } \\
\hline$*$ & - & & 4.47 & جدة & \\
\hline- & & & 4.26 & عرعر & \\
\hline
\end{tabular}




\begin{tabular}{|c|c|c|c|c|c|}
\hline عرعر & 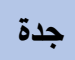 & 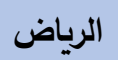 & المتوسط الصسابي & المدينة & المستويات \\
\hline$* *$ & $* *$ & - & 4.65 & 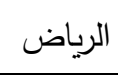 & \multirow{3}{*}{ الممارسات التدريسية في المستوى الثالث } \\
\hline *** & - & & 4.36 & جدة & \\
\hline- & & & 4.00 & عرعر & \\
\hline$* *$ & $* *$ & - & 4.67 & 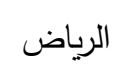 & \multirow{3}{*}{ الممارسات التدريسية في المستوى الرابع } \\
\hline * & - & & 4.50 & جدة & \\
\hline- & & & 4.18 & عرعر & \\
\hline$* *$ & *** & - & 4.69 & 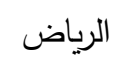 & \multirow{3}{*}{ الممارسات التدريسية في جميع المستويات } \\
\hline *** & - & & 4.44 & جدة & \\
\hline- & & & 4.14 & عرعر & \\
\hline
\end{tabular}

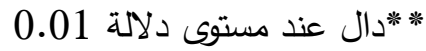
يتضح من الجدول رقم (10) ما يلي: أن هنالك فرقاً دال إحصائياً بين مدن الرياض وجدة وعرعر في في الممارسات التدريسية في المستوى الأول، والثاني، والثالث والرابع

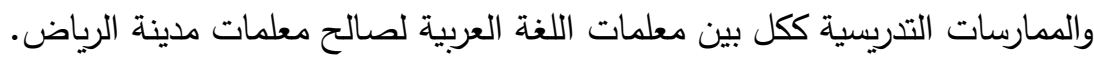
أن هنـاك فرقـاً دال إحصـائياً بـين مدينتي جدة وعرعـر في الممارسـات التدريسية في المستوى الأول والثاني، والثالث والرابع والممارسات التدريسية ككل بين معلمات اللغة العربية لصالح معلمات مدينة جدة.

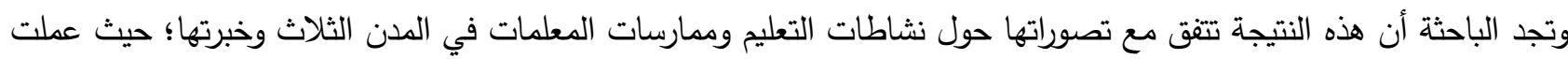
معلمة في مدينة جدة ومارست الإشراف الميداني على طالبات كلية التربية في مرحلة التدريب الميداني في مدينتي الرياض وعرعر

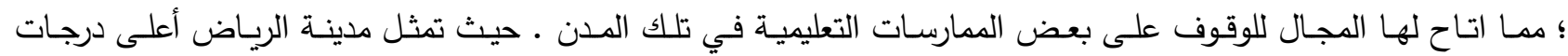

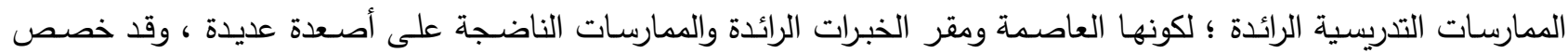
الموقع الإكتروني الرسمي لإدارة التعليم في منطقة الرياض صفحة خاصـة بالاختبارات الدولية ومنها "بيرلز " وتتضمن تدريبات ونموذج وشروحات موجهة للمعلمين ، كما أطلق المركز الوطني للتطوير المهني للمعلمين في عامي 2019 و 2020 سلسة من بن لإنسات الدورات التدريبية للمعلمين في مناطق المملكة العربية السعودية ، ومنها ما اختص بالاختبارات الدولية ـ كما تحظى مدينة جدة

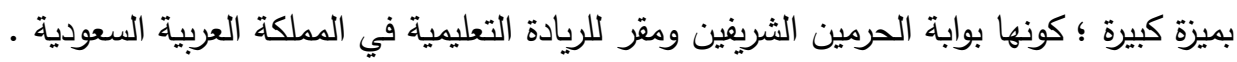

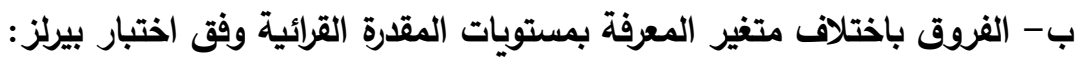
جدول رقم (11)

نتائج اختبار " ت: Independent Sample T-test " للفروق في متوسطات إجابات مفردات عينة الاراسة طبقاً إلى اختلاف متغير المعرفة بمستويات المقدرة القرائية وفق اختبار بيرلز ميطز

\begin{tabular}{|c|c|c|c|c|c|c|}
\hline الدلالة & قيمة ت & الانحراف المعياري & المتوسط الحسابي & العدد العد & المعرفة & المستويات \\
\hline \multirow[b]{2}{*}{$* 0.022$} & \multirow[b]{2}{*}{2.310} & 0.386 & 4.72 & 230 & لدي معرفة واطلاع & \multirow{2}{*}{ في المستوى الأول } \\
\hline & & 0.649 & 4.59 & 170 & ليس لاي معلومات عن الاختبار الدولي & \\
\hline 0.895 & $0.131-$ & 0.521 & 4.60 & 230 & لدي معرفة واطلاع & الممارسات التدريسية \\
\hline
\end{tabular}

424 IUG Journal of Educational and Psychology Sciences (Islamic University of Gaza) / CC BY 4.0 


\begin{tabular}{|c|c|c|c|c|c|c|}
\hline 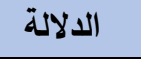 & قيمة ت & الانحراف المعياري & المتوسط الحسابي & العدد العد & المعرفة & المستويات \\
\hline & & 0.421 & 4.61 & 170 & ليس لاي معلومات عن الاختبار الدولي & في المستوى الثاني \\
\hline \multirow[b]{2}{*}{$* 0.031$} & \multirow[b]{2}{*}{$2.168^{-}$} & 0.686 & 4.46 & 230 & لدي معرفة واطلاع & \multirow[b]{2}{*}{ في المستوى الثالث التدريسية } \\
\hline & & 0.461 & 4.59 & 170 & ليس لدي معلومات عن الاختبار الدولي & \\
\hline \multirow[b]{2}{*}{$* 0.024$} & \multirow[b]{2}{*}{$2.272-$} & 0.816 & 4.51 & 230 & لدي معرفة واطلاع & \multirow[b]{2}{*}{ في المستوى الرابع } \\
\hline & & 0.451 & 4.67 & 170 & ليس لدي معلومات عن الاختبار الدولي & \\
\hline \multirow[b]{2}{*}{0.162} & \multirow[b]{2}{*}{$1.401-$} & 0.619 & 4.54 & 230 & لدي معرفة واطلاع & \multirow[b]{2}{*}{ في جميع المستويات التدريسية } \\
\hline & & 0.425 & 4.61 & 170 & ليس لدي معلومات عن الاختبار الدولي & \\
\hline
\end{tabular}

$$
\text { يتضح من الجدول رقم (11) ما يلي: }
$$

عدم وجود فروق ذات دلالة إحصائية عند مستوى الدلالة الإحصائية (0.05) فأقل في إجابات مفردات عينة الدراسة حول (واقع ممارسات معلمات اللغة العربية التدريسية في المملكة العربية السعودية لتتمية المقدرة القرائية للطالبات وفق مؤشرات اختبار بيرلز ، في المستوى الثاني، وجميع المستويات) باختلاف متغير المعرفة بمستويات المقدرة القرائية وفق اختبار بيرلز .

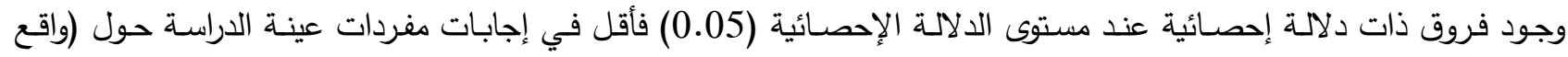

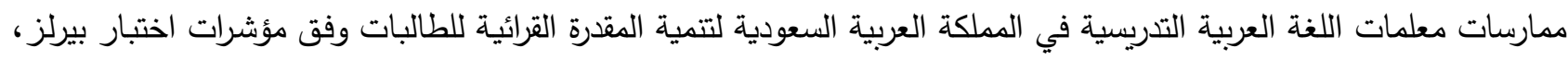
في المستوى الأول) باختلاف متغير المعرفة بمستويات المقدرة القرائية وفق اختبار بيرلز، لصالح المعلمات اللاتي لديهن معرفة واطلاع. وجود فروق ذات دلالـة إحصـائية عند مستوى الدلالـة الإحصـائية (0.05) فأقل في إجابات مفردات عينـة الدراسـة حول (واقع

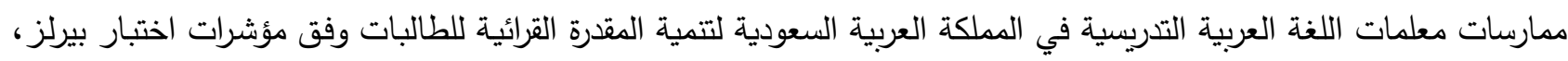

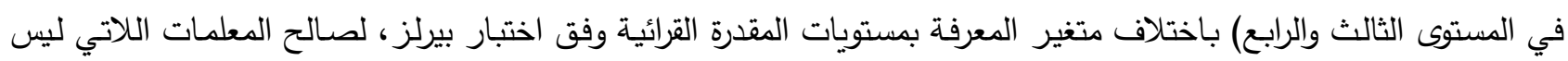

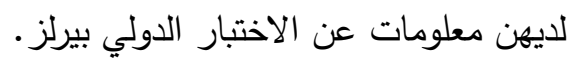

ج-الفروق باختلاف متغير وسيلة المعرفة بمستويات المقدرة القرائية وفق اختبار بيرلز : جدول رقم (12) (12)

نتائج " تحليل التباين الأحادي " (ANOVA Way One) للفروق في إجابات مفردات عينة الدراسة طبقاً إلى اختلاف وسيلة المعرفة بمستويات المقدرة القرائية وفق اختبار بيرلز

\begin{tabular}{|c|c|c|c|c|c|c|}
\hline الإحصائية & قيمة ف & المتوسطات & 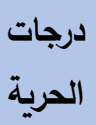 & مربعات & مصدر التباين & المستويات \\
\hline \multirow{3}{*}{0.086} & \multirow{3}{*}{2.467} & 0.656 & 2 & 1.313 & بين المجموعات & \multirow{3}{*}{ الممارسات التدريسية في المستوى } \\
\hline & & 0.266 & 397 & 105.625 & داخل المجموعات & \\
\hline & & & 339 & 106.938 & المجموع & \\
\hline
\end{tabular}




\begin{tabular}{|c|c|c|c|c|c|c|}
\hline الإلإلائة & قيمة ف & المربعات & الحرية & مجبعوع مجبع & مصدر التباين & المستويات \\
\hline \multirow{3}{*}{ ***0.003 } & \multirow{3}{*}{5.862} & 1.320 & 2 & 2.641 & بين المجموعات & \multirow{3}{*}{ لممارسات التدريسية في المستوى } \\
\hline & & 0.225 & 397 & 89.408 & داخل المجموعات & \\
\hline & & & 339 & 92.049 & المجموع & \\
\hline \multirow{3}{*}{$* * 0.000$} & \multirow{3}{*}{8.398} & 2.948 & 2 & 5.895 & بين المجموعات & \multirow{3}{*}{ لممارسات التدريسية في المستوى } \\
\hline & & 0.351 & 397 & 139.355 & داخل المجموعات & \\
\hline & & & 339 & 145.250 & المجموع & \\
\hline \multirow{3}{*}{$* * 0.000$} & \multirow{3}{*}{19.325} & 8.403 & 2 & 16.807 & بين المجموعات & \multirow{3}{*}{ لممارسات التدريسية في المستوى } \\
\hline & & 0.435 & 397 & 172.633 & داخل المجموعات & \\
\hline & & & 339 & 189.440 & المجموع & \\
\hline \multirow{3}{*}{$* * 0.000$} & \multirow{3}{*}{10.476} & 2.977 & 2 & 5.954 & بين المجموعات & \multirow{3}{*}{ الممارسات التدريسية في جميع } \\
\hline & & 0.284 & 397 & 112.819 & داخل المجموعات & \\
\hline & & & 339 & 118.773 & المجموع & \\
\hline
\end{tabular}

*2:دلالة إحصائية عند مستوى 0.05 فاقل

يتضـح من الجدول رقم (12): عدم وجود فروق ذات دلالة إحصائية عند مستوى الدلالة الإحصائية (0.05) فأقل في إجابات مفردات عينة الدراسة حول (الممارسات التدريسية في المستوى الأول) باختلاف متغير وسيلة المعرفة بمستويات المقدرة القرائية وفق إلق

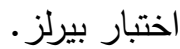
كما يتضـح من الجدول رقم (12): وجود فروق ذات دلالمة إحصـائية عند مستوى الدلالة الإحصـائية (0.01) فأقل في إجابات مفردات عينة الدراسة حول (الممارسات التدريسية في المستوى الثاني، والثالث والرابع والممارسات التدريسية ككل) باختلاف متغير وسيلة المعرفة بمستويات المقدرة القرائية وفق اختبار بيرلز • وتم إجراء تحليل بعدي باستخدام اختبار أقل فرق معنوي " LSD "وجاءت النتائج كما يأتي:

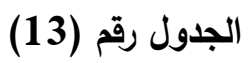

المقارنات البعدية على الممارسات التدريسية في المستوى الثاني، والثالث والرابع والممارسات التدريسية ككل " LSD" للفروق

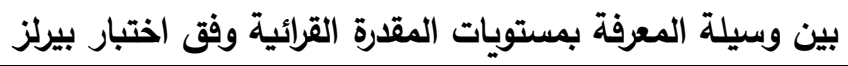

\begin{tabular}{|c|c|c|c|c|c|}
\hline التربود الإشراف & من خلال & تدري خلات & المسابي & الوسيلة & المستويات \\
\hline & & - & 4.43 & من خلال دورات تدريبية في الاختبارات & \multirow{2}{*}{ في المستوى الثاني } \\
\hline & - & $* *$ & 4.65 & من خلال التعاميم والمنشورات الرسمية من & \\
\hline
\end{tabular}




\begin{tabular}{|c|c|c|c|c|c|}
\hline التربود الإشراف & من خلال & تدريبة خلال & الحتوسط المسب & الوسيلة & المستويات \\
\hline \multirow[t]{3}{*}{-} & & $* *$ & 4.63 & جهود الإشراف التربوي والمدرسة & \\
\hline & & - & 4.25 & من خلال دورات تدريبية في الاختبارات & \multirow{3}{*}{ في المستوى الثالث } \\
\hline & - & $* *$ & 4.55 & من خلال التعاميم والمنشورات الرسمية من & \\
\hline \multirow[t]{3}{*}{-} & & $* *$ & 4.58 & جهود الإشراف التربوي والمدرسة & \\
\hline & & - & 4.14 & من خلال دورات تدريبية في الاختبارات & \multirow{3}{*}{ في المستوى الرابع التدريسية } \\
\hline & - & $* *$ & 4.62 & من خلال التعاميم والمنشورات الرسمية من & \\
\hline \multirow[t]{3}{*}{-} & & $* *$ & 4.70 & جهود الإشراف التربوي والمدرسة & \\
\hline & & - & 4.31 & من خلال دورات تدريبية في الاختبارات & \multirow{3}{*}{ في جميع المستويات المدارسات } \\
\hline & - & $* *$ & 4.60 & من خلال التعاميم والمنشورات الرسمية من & \\
\hline- & & $* *$ & 4.64 & جهود الإشراف التربوي والمدرسة & \\
\hline
\end{tabular}

0.01 (دال عند مستوى دلالة

$$
\text { يتضح من الجدول رقم (13) ما يلي: }
$$

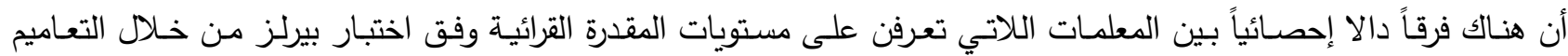
والمنشورات الرسمية من وزارة التعليم، والمعلمات اللاتي تعرفن على مستويات المقدرة القرائية وفق اختبار بيرلز من خلال دورات تدريبية في الاختبارات الدولية حول الممارسات التدريسية في المستوى الثاني، والثالث والرابع والممارسات التدريسية ككل لصالح المعلمات اللاتي تعرفن على مستويات المقدرة القرائية وفق اختبار بيرلز من خلال التعاميم والمنشورات الرسمية من وزارة التعليم. كما كثف الجدول أعلاه أن هنالك فرقاً دالا إحصائياً بين المعلمات اللاتي تعرفن على مستويات المقدرة القرائية وفق اختبار بيرلز من خلال جهود الإثراف التربوي والمدرسة، والمعلمات اللاتي تعرفن على مستويات المقدرة القرائية وفق اختبار بيرلز من خلال دورات تدريبية في الاختبارات الدولية حول الممارسات التدريسية في المستوى الثاني، والثالث والرابع والممارسات التدريسية ككل لصالح المعلمات اللاتي تعرفن على مستويات المقدرة القرائية وفق اختبار بيرلز من خلال جهود الإشراف التربوي والمدرسة. وتعكس هذه النتيجة الجهود الكبيرة التي بذلتها وزارة التعليم في المملكة العربية السعودية وهيئة تقويم التعليم في سبيل رفع الوعي في البيئة التعليمية بالاختبارات الدولية عامة واختبار بيرلز خاصة، وتوجيه جهود المعلمين إلى رفع القدرة القرائية لاى الطلاب؛ كونها مدخلا للفهم والتحصيل والوعي • وقد تتوعت هذه الجهود بدءا بلقاء وزير التعليم في المملكة العربية السعودية الدكتور حمد آل الثيخ الذي واكب توليه مقاليد الوزارة واستدعى فيه القيادات في مناطق التعليم في المملكة العربية السعودية ليؤكد أن الاهتمام بنتائج الطلاب في الاختبارات الدولية من أولويات أعمال التعليم في المملكة العربية السعودية في الفترة ؛ لتكون انعكاسا للجهود الجادة لتحسين مخرجات التعلم ، وانتهاء بدعم الممارسات المثلى لرفع المقدرة القرائية من المعلمين في مختلف المناطق ، وتطويه آليات مراقبة جودة مخرجات التعليم ، وتوفير الفرص التدريبية على ذلك. 


\section{4-التعليق على نتائج الاراسة:}

تكثف إجابات العينة عن درجات عالية في الممارسات التتريسية الهادفة إلى تتمية المقدرة القرائية، وهذه النتيجة التي تعارض ما أسفرت عنه التقارير الرسمية عن نتائج مشاركة المملكة العربية السعودية في اختبار (بيرلز)، وتفسر الباحثة ذلك بعدم وعي العينة بمستويات الاختبار وبالمؤشرات التي تحقق كل مستوى. ويتقق هذا التقسير مع توصيات دراسة الثنقيطي (2020) بضرورة تقديم

برامج تدريبية للمعلمات لزيادة وعيهن بالاختبارات الدولية.

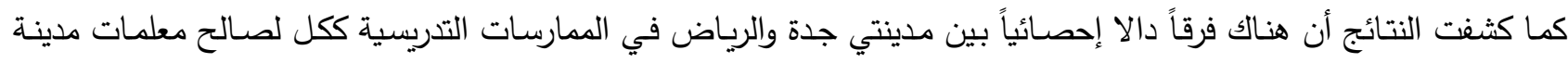
الرياض، وتقسر الباحثة ذلك بتكثيف الجهود في التدريب والتوعية في مدينة الرياض.

كما أظهرت النتائج وجود فروق ذات دلالة إحصائية في إجابات مفردات عينة الدراسة حول (واقع ممارسات معلمات اللغة العربية

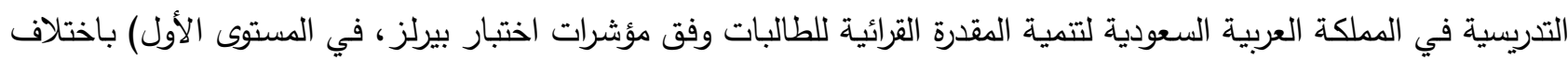
متغير المعرفة بمستويات المقدرة القرائية وفق اختبار بيرلز ، لصالح المعلمات اللاتي لديهن معرفة واطلاع. وكذلك وجود فروق ذات دلالة إحصائية في إجابات مفردات عينة الدراسة حول (واقع ممارسات معلمات اللغة العربية التدريسية في لئي المملكة العربية السعودية لتمية المقدرة القرائية للطالبات وفق مؤشرات اختبار بيرلز ، في المستوى الثالث والرابع) باختلاف متغير المعرفة بمستويات المقدرة القرائية وفق اختبار بيرلز، لصالح المعلمات اللاتي ليس لديهن معلومات عن الاختبار الدولي بيرلز .

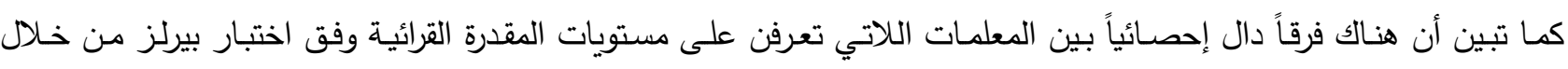
التعاميم والمنشورات الرسمية من وزارة التعليم، والمعلمات التلاتي تعرفن على مستويات المقدرة القرائية وفق اختبار بيرلز من خلال

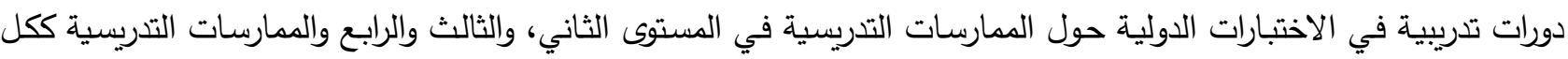
لصالح المعلمات اللاتي تعرفن على مستويات المقدرة القرائية وفق اختبار بيرلز من خلال التعاميم والمنشورات الرسمية من وزارة التعلي阝. وأن هناك فرقاً دال إحصائياً بين المعلمات اللاتي تعرفن على مستويات المقدرة القرائية وفق اختبار بيرلز من خلال جهود الإثراف

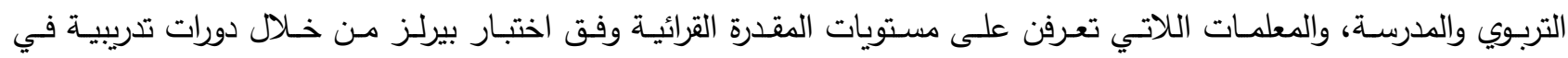

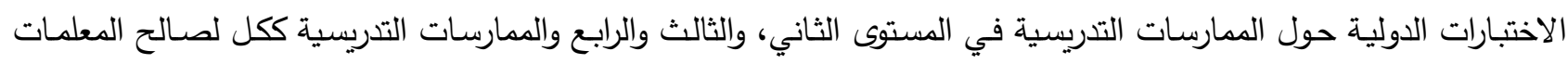
اللاتي تعرفن على مستويات المقدرة القرائية وفق اختبار بيرلز من خلال جهود الإثراف التربوي والمدرسة. وتكثف هذه الدراسة -بشكل غير مباشر -عن وجود نقص في وعي العينة بمستويات اختبار المقدرة القرائية ،التي تمثل أزمـة حقيقة في التعليم في وطننا العربي في الوقت الحالي ،وتتفق هذه النتيجة مع الدراسات العربية التي تتاولت اختبار بيرلز ،حيث

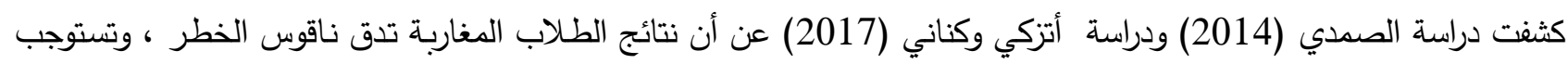
من الجهات القائمة على التعليم بذل جهود مكثقة لبناء استراتيجية الفهم لدى المتعلمين ، وقيام معلمي اللغات بمسئوليتهم العظيمة ودورهم الكبير في معالجة مكون القراءة ،وتكوين المقدرة القرائية وفق المحكات العالمية . رابعاً: توصيات الاراسة ومقترحاتها.

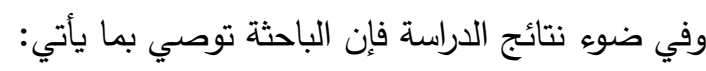
-تبني خطة وطنية قائمة على العمل المنهج لتتمية وعي المعلمين بمؤشرات اختبار بيرلز والاختبارات الدولية المشابهة. -تبني الدراسات التي تتظر إلى المقدرة القرائية كمدخل للفهم والتعلم وجودة الحياة للمتعلمين، وعدم اقتصار جهود تتميتها على لئ لئل تعليم اللغة العربية . - إجراء البحوث والدراسات التتبعية للكثف عن ممارسات المعلمين والمعلمات وربطها بنتائج الاختبارات الدولية. 
- عقد دورات لتدريب المعلمين والمعلمات في أثثاء الخدمة بهذف تتمية مهارات المعلمين في الارتقاء بالمقدرة القرائية لاى طلابهم، مع قياس أثر التدريب.

\section{وتقترح الباحثة إجراء الداسات الآتية:}

- إجراء دراسات تربط نتائج الاختبار الدولي في المقدرة القرائية بعدة عوامل منها ما يتعلق بالطالب أو المعلم أو المنهج أو الأسرة

والمجتمع.

- انطلاق الدراسات والبحوث من الواقع التعليمي في الفصل الدراسي، ومن الممارسات المجتمعية. - إجراء دراسات تقارن بين ممارسات معلمي اللغات المثلى (العربية كلغة أم والإنجليزية كلغة ثانية) في تتمية المقدرة القرائية.

\section{المصادر والمراجع}

المراجع العربية:

أتزكي، أحمد؛ كناني ،رشيد (2017). القراءة من منظور الدراسة الدولية بيرلز • دراسات بيداغوجية. ع. 1، يناير 2017 .ص

ص 207-21-

أحمد، جابر أحمد. (2002م). تنمية بعض مهارات ما وراء المعرفة لدى الطلاب المعلمين بكلية التربية بسوهاج. القاهرة: جامعة عين شمس الجمعية المصرية للمناهج وطرق التدري، مجلة دراسات في المناهج وطرق التدريس. العدد (77)، كلية التربية

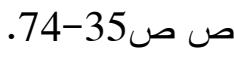
الأدغم، رضا أحمد. (2004م). أثر التدريب على بعض استراتيجيات فهم الدقروء لدى طلاب شعبة اللغة العربية بكليات التربية

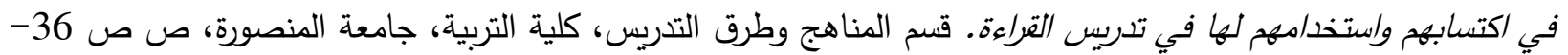

الجرف، ريما سعد. (1423هـ). دراسات في تعليم القراءة بمراحل التعليم العام بالهملكة العربية السعودية. الرياض.

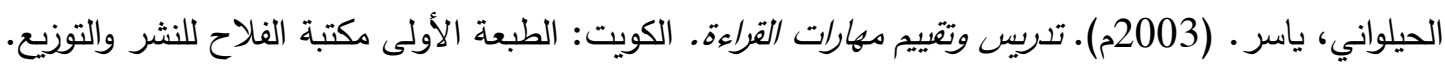
الزعابية ، أمل؛ المحرزي ،عبد الحميد. (2019م). معايرة اختبار الدراسة الدولية لقياس مدى تقدم القراءة (PIRLS) بسلطنة

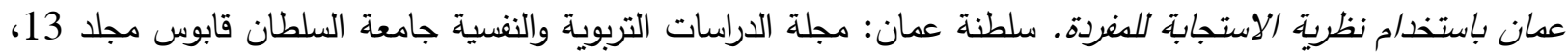
عدد3، ص ص :496-515. الزهراني، سعيد محمد. (1424هـ). تقويم أداء معلمي اللغة العربية في تدريس القراءة الجهرية لتلاميذ الصف السادس الابتدائي بدحافظة جدة. مكة المكرمة: رسالة ماجستير غير منشورة قسم المناهج وطرق التدريس، كلية التربية، جامعة أم القرى. الثنقيطي ، أمامة محمد. (2020). فاعلية برنامج تدريبي في توعية معلمات اللغة العربية بالمعارسات المثلى لرفع الدقدة

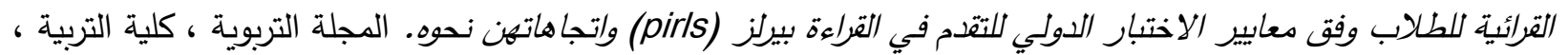

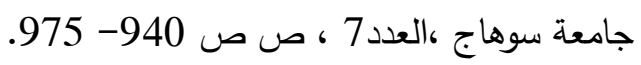

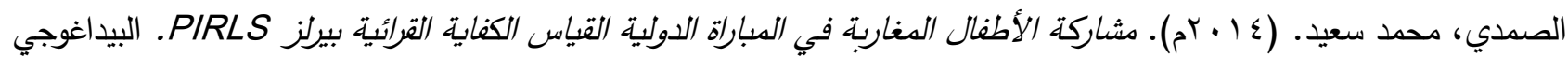

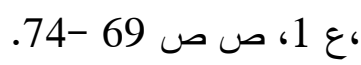

العدوان، نورة عبد الله. (2000))أثر استخدم التعلم التعاوني في تحصيل طالبات الصفوف العليا من الهرحلة الابتدائية في القراءة. الرياض: رسالة دكتوراه غير منشورة.كلية العلوم الاجتماعية، جامعة الإمام محمد بن سعود الإسلامية. العساف، صالح حمد. (2000م). الددخل إلى البحث في العلوم السلوكية ط (2) ـ الرياض: مكتبة العبيكان. 
العويضي، وفاء؛ القحطاني ، عادل. (1441). إستراتيجية تطوير مهارات تعلم التلاميذ في ضوء معايير اختبارت التيمس وبيرلز

$$
\text { وبيزا. جدة : مكتبة الملك فهد الوطنية. }
$$

الفرا، إسماعيل صالح. (2018). واقع مدارسة معلمي اللغة العربية لأدوارهم المتجدة في مجتمع الدعرفة قبل التدربي وفي أثنائه.

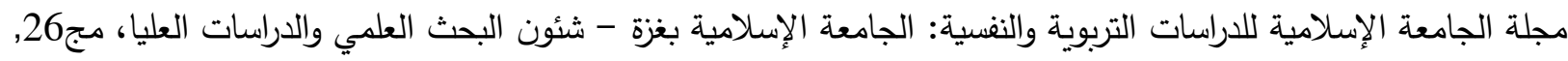

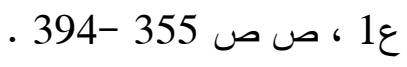

الفقيه، مشاعل محمد. (2003م). مفهوم تعليم القراءة لدى معلمات اللغة العربية بالمرحلة الابتدائية وواقع تعليهن القراءة من

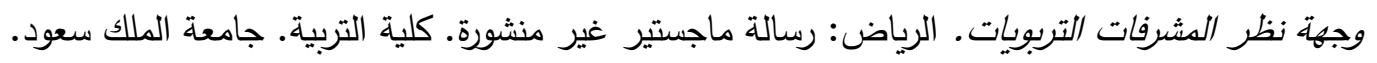

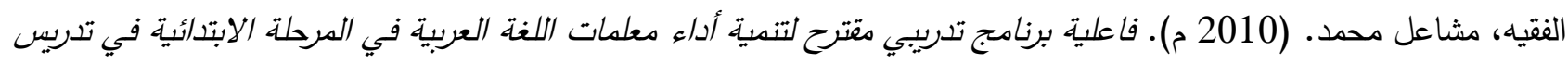

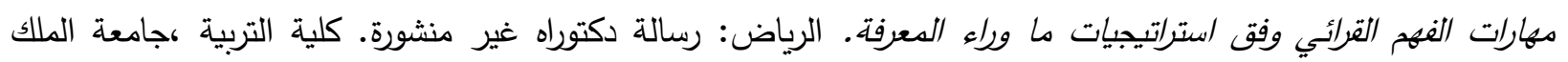
سعود. المركز العربي للبحوث التربوية لدول الخليج. (2016م). مستتبليات تربوية: الدور المتغير للدعلم. الكويت: العدد السادس المركز

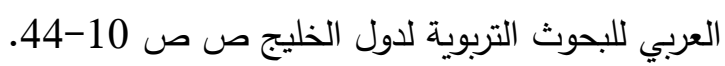
المنتشري، علي احمد عبد الله. (2007م). أثر استخدام استراتيجية التدريس التبادلي في تنمية مهارات الفهم القرائي لدى طلاب الصف الأول المتوسط. أبها: رسالة ماجستير غير منشورة، كلية التربية، جامعة الملك خالد.

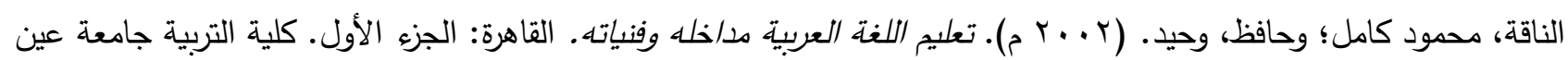
شمس حافظ، حسام الدين. (2001م). دليلك إلى محركات البحث على شبكة الإنترنت. القاهرة: دار الكتب العلمية للنشر والتوزيح، ص6. (1) n حبيب الله، محمد. ( . . . r م). أسس القراءة وفهم الدقروء ببين النظرية والتطبيق.الطبعة الثانية. عمان: دار عمار. دومي، حسن؛ الثناق، قسيم. (2008م). معوقات التعليم الاككتروني في مادة الفيزياء من وجهة نظر الدعلمين والطلبة. مجلة

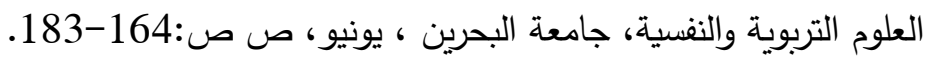

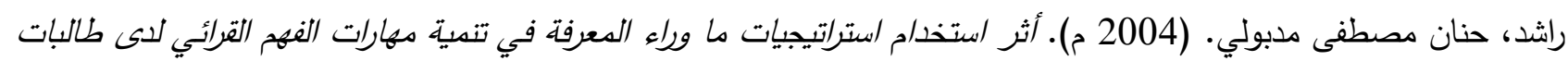
الصف الأول الإعدادي الأزهري. المؤتمر العلمي الرابع للجمعية المصرية للقراءة والمعرفة (القراءة وتتمية التفكير)،كلية التربية، جامعة عين شمس، ص ص الإع الاعدي الأهري. 178-222.

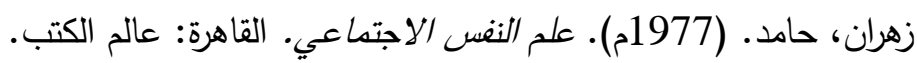
طعيمه، رشدي. (1998م). الأسس العامة لمناهج تعليم اللغة العربية إعدادها وتطويرها وتثويهها. القاهرة: دار الفكر العربي.

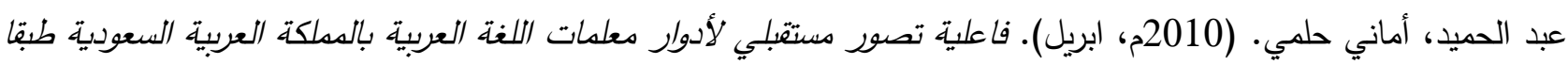

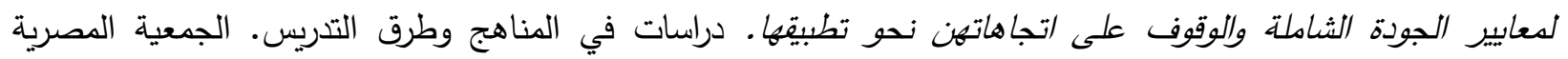

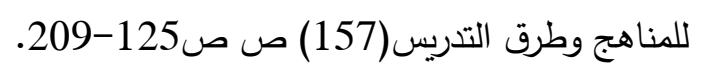
عبد الرحيم، طلعت. (1988م). علم النغس الاجتماعي المعاصر . القاهرة: دار الكتب المصرية. عبدالباري، حسني. (1999م). قضايا في تعليم اللغة العربية وتدريسها ـ الإسكندرية: المكتب العربي الحديث. عثمان، محمد الصائم. (1421هـ). تدريب المعلمين أثناء الخدمة -بعض التجارب المعاصرة. بيثة: مكتبة الخبتي الثقافية.

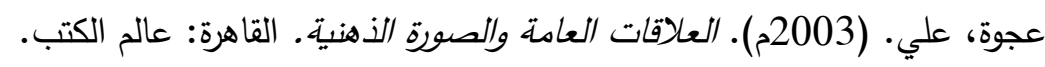
علي ، محمد السيد. (2011). موسوعة الدصطلحات التربوية. عمان : دار المسيرة. 
عوض، فائزة السيد. (1995م). أثر الأسئلة التوجيهية في القراءة الصامتة على تحصيل التلاميذ في القراءة. . مؤتمر التعليم

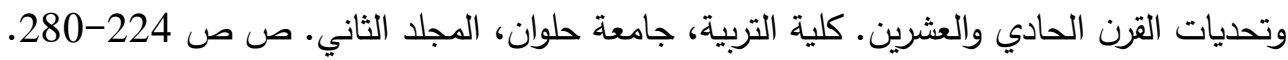

عوض، فائزة السيد؛ والسيد، سعيد محمدي. (2003 م). فعالية بعض استراتيجيات ما وراء الدعرفة في تنمية الفهم القرائي إنتاج الأسئلة والوعي بها وراء الدعرفة في النصوص الأدبية لدى طلاب المرحلة الثانوية. القاهرة: المؤتمر العلمي الثالث. مجلة

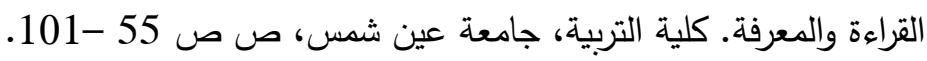

الغامدي، عائشة سعيد علي. (2020). فاعلية استراتيجية التصور الذهني في تنمية مهارات الفهم القرائي والاتجاه نحو القراءة لدى

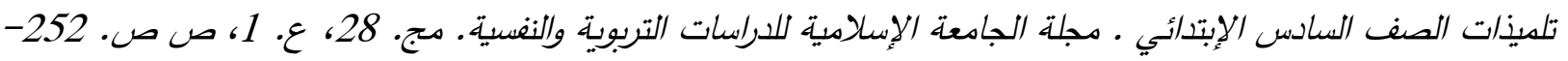

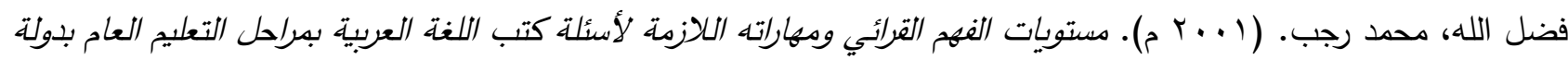

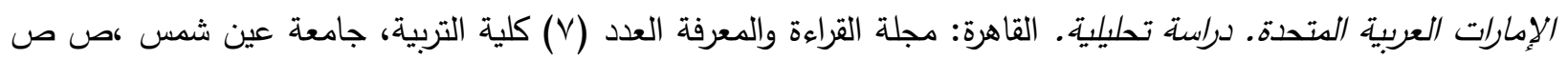

مدكور ،علي أحمد. (2014). المعايير التي ينبغي توفرها في معلم اللغة العربية ، منشور ضمن إصدارات مركز الملك عبدالله بن

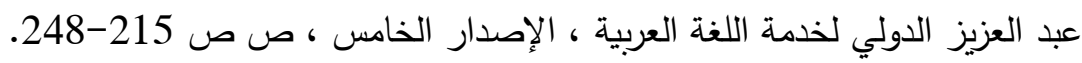
مدكور ، علي أحمد. (Trك اهـ). تدربس فنون اللغة العربية.الطبعة الثانية. القاهرة: دار الفكر العربي. موسى، مصطفى إسماعيل. (2001م). أثر استراتيجية ما وراء المعرفة في تحسين أنهاط الفهم القرائي والوعي بها وراء الدعرفة الفئ

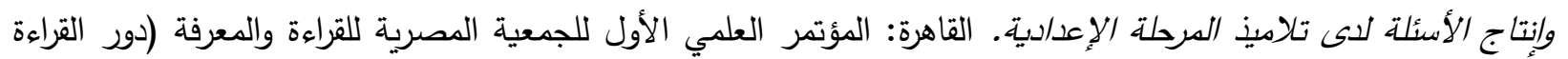

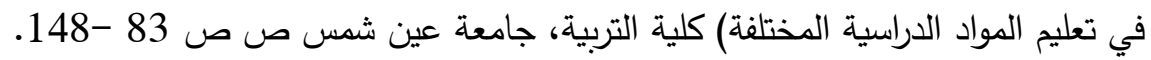
يونس، فتحي. (2001م). استراتيجيات تعليم اللغة العربية في المرحلة الثانوية. القاهرة: مطبعة الكتاب الحديث.

Abdalbari. (1999). Issues in Arabic language education and teaching(in Arabic). Alexandria: Modern Arab Office.

Abdul Hamid, A. H. (2010). The effectiveness of a future vision of the roles of Arabic language parameters in Saudi Arabia according to the overall quality standards and their attitudes toward their application.Studies in curricula and teaching methods(in Arabic). Egyptian Society for Curriculum and Pedagogy p. 125-209.

Abdul Rahim, T. (1988). Contemporary social psychology (in Arabic). Cairo: Egyptian Books House.

Agwa, A. (2003). Public relations and the mental image(in Arabic). Cairo: World of Books.

Ahmed, J. A. (2002). Developing some metacognitive skills for student teachers at the College of Education in Sohag(in Arabic). Cairo: Ain Shams University, Egyptian Association for Curricula and Teaching Methods, Journal of Studies in Curricula and Teaching Methods. Issue (77), College of Education, pp. 35-74.

AL- Naqah, M. K. (2002). Teaching the Arabic language its entries and techniques(in Arabic). Part One. Faculty of Education, Ain Shams University. Cairo.

AL-Adgham, R. (2004 AD). The effect of training on some strategies for reading comprehension among students of the Arabic Language Division at Faculties of Education in their acquisition and use of it in teaching reading (in Arabic). Department of Curricula and Teaching Methods, College of Education, Mansoura University, pp. 36-81. 
Al-Awaidi, W., \& Al-Qhahtani, A. (1441). Strategy to develop student learning skills in light of the criteria for testing of Times, Perles and Pisa (in Arabic). Jeddah: King Fahd National Library.

Al-Eddwan, N. A. (2000). The effect of using cooperative learning in the achievement of highergrade students in reading(in Arabic). Unpublished Ph.D. thesis. Riyadh: Faculty of Social Sciences, Imam Mohammed Bin Saud Islamic University.

Al-Faqih, M. M. (2003). The concept of reading education in Arabic at the primary level and the reality of their reading education from the point of view of the educational supervisors (in Arabic).Unpublished Master's Message. Faculty of Educatin. Riyadh.

Al-Faqih, M. M. (2010). The effectiveness of a proposed training program to develop the performance of Arabic language parameters at the primary level in teaching the skills of reading understanding according to the strategies beyond knowledg (in Arabic)Unpublished Ph.D. Message. Riyadh: Faculty of Education, King Saud University.

Alfra, I. S. (2018). The reality of Arabic language teachers' practice of their renewed roles in the knowledge society before and during instruction. Islamic University Journal of Educational and psychological Studies(in Arabic). Islamic University of Gaza -Scientific Research and Graduate Studies, Maj26, I, pp. 355-394.

Alghamdi, A. .. (2020). Effectiveness of a mental imagery strategy in developing reading and reading skills for sixth-grade students (in Arabic). Journal of the Islamic University for Educational and psychological Studies. Program. 28, p. 1, p. 252-281.

Al-Helwani, Y. (2003). Teaching and assessment of reading skills (in Arabic). First Edition Al Falah Library for Publishing and Distribution. Kuwait.

Ali, M. A. (2011). Encyclopedia of Educational terms (in Arabic). Amman: House of March.

Al-Jarf, R. S. (1423). Studies in reading education in general education stages in the Kingdom of Saudi Arabia(in Arabic). Riyadh.

Al-Manshari, A. (2007). The effect of using a reciprocal teaching strategy on developing the reading understanding skills of Grade 7 students(in Arabic). Unpublished Master's Message, Faculty of Education, King Khaled University. Abha.

Al-Shankyty, O. M. (2020). The effectiveness of a training program in educating Arabic language teachers about best practices to raise students' reading ability in accordance with the standards of the International Test for Progress in Reading (Pirls) and their attitudes towards it. (in Arabic)The educational magazine, College of Education, Sohag University, Issue 7, pp. 940975.

Al-Zahrani, S. M. (1424). Evaluating the performance of Arabic language teachers in teaching aloud reading to sixth grade pupils in Jeddah governorate(in Arabic). Unpublished Master Thesis. Makah Al-Mukarramah: Department of Curricula and Teaching Methods, College of Education, Umm Al-Qura University.

Arab Center for Educational Research in the Gulf States. (2016). Educational Futures: The changing role of the Teacher Kuwait: 6th issue(in Arabic), Arab Center for Educational Research for the Gulf States, pp. 10-44.

Assaf, S. H. (2000). The entry into research in the behavioral sciences I (2)(in Arabic). Riyadh: AlAbikan Library.

Awad, F. A. (1995). The impact of the Guiding Questions on Silent Reading on students' reading. The Conference on Education and the challenges of the Twenty-first century (in Arabic). Faculty of Education, University of Hellwan, vol. II. P. 224-280.2.

Awad, F., \& AL-Saeed, M. (2003). The effectiveness of some knowledge-beyond strategies in developing reading understanding producing questions and awareness of what is beyond knowledge in literary texts in high school students (in Arabic). Cairo: Third Scientific Conference. Reading and knowledge magazine. Faculty of Education, Ain Shams University, pp. 55-101. 
Domy, H., \& Al-Shanaq, Q. (2008). Obstacles to electronic instruction in physics from the point of view of teachers and students (in Arabic). Journal of Educational and psychological Sciences, University of Bahrain, June, pp. 164-183.

Fadlallah, M. R. (2001). Levels of reading comprehension and skills required for questions of Arabic language books at the general education stages in the United Arab Emirates. Analytical study (in Arabic). Cairo: The Journal of Reading and knowledge No7, Faculty of Education, Ain Shams University, pp. 85-118.

Habib Allah, M. (2000). Bases reading and reading understanding between theory and practice.2nd Edition(in Arabic). Amman: Dar Ammar.

Hafiz, H. (2001). Your guide to online search engines (in Arabic). Cairo: Science Books for Publishing and Distribution, p. 6.

Izzaki, A., \& Kanani, R. (2017). Reading from the Perspective of International Study Pirls (in Arabic). Pedagogical studies. P. 1, January 2017. pp. 207-221.

Madkor, A. A. (1423). Teaching the Arts of Arabic.2nd edition (in Arabic). Cairo: Arab thought House.

Madkor, A. A. (2014). Standards to be available in Arabic Language Teacher(in Arabic), published in the Publications of King Abdullah Bin Abdul Aziz International Center for Arabic Language Service, 5th Edition, pp. 215-248.

Musa, M. I. (2001). The impact of the beyond-knowledge strategy on improving reading understanding patterns, knowledge awareness, and the production of questions for preparatory students(in Arabic). Cairo: First Scientific Conference of the Egyptian Society for Reading and knowledge (the role of Reading in Teaching different subjects), Faculty of Education, Ain Shams University, pp. 83-148.

Othman, M. A. (1421). In-service teacher training-some contemporary experiences (in Arabic). Beicha: The cultural library of the bibliotheca.

Rashid, H. M. (2004). The effect of using beyond knowledge strategies on developing the skills of reading understanding of Azhari first-grade students.Fourth Scientific Conference of the Egyptian Society for Reading and knowledge (Reading and developing Thinking)(in Arabic). Faculty of Education, Ain Shams University, pp. 178-222.

Samadi, M. S. (2010). The participation of Moroccan children in the international match the measurement of PIRLS reading efficiency (in Arabic). Pidagogi, p 1, p. 69-74.

Taima, R. (1998). The general principles of Arabic language teaching methods for their preparation, development and evaluation(in Arabic). Cairo: Arab thought House.

Younis, F. (2001). Strategies for teaching Arabic at the secondary level(in Arabic). Cairo: Modern Book Press.

Zaabi, A., \& Al-Mahrezi, A. (2019). Calibration of the PIRLS test in the Sultanate of Oman using the singular response theory(in Arabic). Sultanate of Oman.

Zahran, H. (1977). Social psychology (in Arabic). Cairo: World of Books.

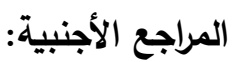

C. E \& ,Azevedo, Ri Hmelo-Silver (2006) .Understanding Why the New Zealand National Literacy Strategy has failed and what can be done about it: Evidence from the Progress in International Reading Literacy Studly (PIRLS) 2011 and Reading Recovery monitoring reports.complex systems: Some core cha .The Journal of the learning sciences, 53-61.

I Abd El Hack .(2006) .The Effectiveness of Using Reciprocal Teaching inImproving Strategic Reading and Reading Comprehension Skills of EFL.Majors Studies in Curriculum and Instruction N.35-113,1 . 
John, Jerrim. Luis, Alejandro. Lopez, Agudo(2020) The association between homework and primary school children's academic achievement. International evidence from PIRLS and

Lenkeit ،Jenny Therese N. Hopfenbeck؛ Shailen Popat .(2017) .PIRLS for Teachers: A review of practitioner engagement with international large-scale assessment results .Oxford University Centre for Educational Assessment Report OUCEA/17/1

M. Leno .(2002).An extension of the IRT to a network model .Benazilitarika: 29(1), 59-79.

$\mathrm{N} \&$,.Kitsantas, A Dabbach .(2005) .Using web-based pedagogical tools as scaffolds for selfregulated.

P. H Winne .(1997) .Experimenting to bootstrap self-regulated learning .Journal of Educational Psychology, 89, 327-353.

P., Martin, 0, Mullis, V, S \& ,.Stanco, G, Foy .(2011) .Metlaods and procedures- recieving the TIMSS and PIRLS 2011 achienerment itein statistics .Chestnut Hill: Boston College. Retrieved from http:tirssandpirls.bc.edu, 18/12/2016.

R., Cromley, J. G \& ,.Seibert, D Azevedo .(2004) .Does adaptive scaffolding facilitate students' ability to regulate their learning with hypermedia? Contemporary Educational Psychology,29 . $.370-344$

Ratri .S. Y (2015) .Student factor infl uencing Indonesian student reading literacy based on PIRLS data 2011 .Journal of Education, 1 (1), 24-32.

TIMSS. wileyonlinelibrary.com/journal/ejed

WV, E., Chapman, J. W. Greaney, K, T., Prochnow, J. E \& ,.Arrow, A. W. 9. Tunmer .(2013) . Australiaira Jatrial of Learning Difficulties.180-139,(2)18 .

Zimmerman .L (2014) .Lessons learnt: Observation of Grade 4 reading comprehension teaching in South African schools across the Progress in International Reading Literacy Study (PIRLS) 2006 achievement spectrum .Reading \& Writing-Journal of the Reading Association of South Africa, 5. Learning. Instructional Science.540-513. 